\title{
Review
}

\section{Chemical Strategies for Controlling Protein Folding and Elucidating the Molecular Mechanisms of Amyloid Formation and Toxicity}

\author{
Sara Butterfield, Mirva Hejjaoui $\nmid$, Bruno Fauvet $\dagger$, Loay Awad \\ and Hilal A. Lashuel ${ }^{*}$
}

Laboratory of Molecular and Chemical Biology of Neurodegeneration, Brain Mind Institute, School of Life Sciences, Ecole Polytechnique Fédérale de Lausanne, CH-1015 Lausanne, Switzerland

Received 29 December 2011; received in revised form

30 January 2012;

accepted 31 January 2012

Available online

14 February 2012

\section{Edited by S. Radford}

Keywords:

amyloid;

fibrils;

chemical biology;

neurodegenerative diseases; posttranslational

modifications
It has been more than a century since the first evidence linking the process of amyloid formation to the pathogenesis of Alzheimer's disease. During the last three decades in particular, increasing evidence from various sources (pathology, genetics, cell culture studies, biochemistry, and biophysics) continues to point to a central role for the pathogenesis of several incurable neurodegenerative and systemic diseases. This is in part driven by our improved understanding of the molecular mechanisms of protein misfolding and aggregation and the structural properties of the different aggregates in the amyloid pathway and the emergence of new tools and experimental approaches that permit better characterization of amyloid formation in vivo. Despite these advances, detailed mechanistic understanding of protein aggregation and amyloid formation in vitro and in vivo presents several challenges that remain to be addressed and several fundamental questions about the molecular and structural determinants of amyloid formation and toxicity and the mechanisms of amyloid-induced toxicity remain unanswered. To address this knowledge gap and technical challenges, there is a critical need for developing novel tools and experimental approaches that will not only permit the detection and monitoring of molecular events that underlie this process but also allow for the manipulation of these events in a spatial and temporal fashion both in and out of the cell. This review is primarily dedicated in highlighting recent results that illustrate how advances in chemistry and chemical biology have been and can be used to address some of the questions and technical challenges mentioned above. We believe that combining recent advances in the development of new fluorescent probes, imaging tools that enabled the visualization and tracking of molecular events with advances in organic synthesis, and

\footnotetext{
${ }^{*}$ Corresponding author. E-mail address: hilal.lashuel@epfl.ch.

$\dagger$ M.H. and B.F. contributed equally to this work.

Abbreviations used: $A \beta$, amyloid- $\beta$; IAPP, islet amyloid polypeptide; ThT, thioflavin T; TFA, trifluoroacetic acid; TEM, transmission electron microscopy; DMDA, N,N-dimethylethylenediamine; PEG, polyethylene glycol; CNB, $\alpha$-carboxyl-2nitrobenzyl; LMW, low molecular weight; AD, Alzheimer's disease; PICUP, photoinduced protein cross-linking of unmodified proteins; tfmd, trifluoromethyldiazirine; SPPS, solid-phase peptide synthesis; PTM, posttranslational modification; LB, Lewy body; NCL, native chemical ligation; EPL, expressed protein ligation; TEV, tobacco etch virus; $\alpha$ syn, $\alpha$-synuclein; PD, Parkinson's disease; GPI, glycosylphosphatidylinositol; DOPC, dioleoyl-sn-glycero-3phosphocholine; SUV, small unilamellar vesicle; CPP, cell-penetrating peptide.
} 
novel approaches for protein synthesis and engineering provide unique opportunities to gain a molecular-level understanding of the process of amyloid formation. We hope that this review will stimulate further research in this area and catalyze increased collaboration at the interface of chemistry and biology to decipher the mechanisms and roles of protein folding, misfolding, and aggregation in health and disease.

(C) 2012 Elsevier Ltd. All rights reserved.

\section{Introduction}

Protein misfolding and aggregation (more specifically, amyloid formation) play central roles in the pathogenesis of several incurable systemic and neurodegenerative diseases that affect the aging population today. These diseases include neurodegenerative disorders such as Alzheimer's disease (AD), Parkinson's disease (PD), Prion diseases, and Huntington's disease, as well as systemic diseases such as type 2 diabetes, systemic amyloidosis, and light-chain amyloidosis. The amino acid sequence and the molecular and cellular determinants that govern protein misfolding, oligomerization, and fibrillogenesis in vivo remain poorly understood. Furthermore, the mechanisms by which these processes contribute to neurodegeneration and cell death, as well as the identity of the pathogenic species, have not been determined. Therefore, a detailed understanding of the molecular mechanisms underlying these processes inside and outside the cell is of critical importance for elucidating the fundamental rules that govern protein misfolding and aggregation and for the development of effective therapeutic strategies for the treatment and/or prevention of these devastating diseases.

To understand the molecular basis of any biological process, including amyloid formation and toxicity, it is critical to be able not only to visualize and monitor molecular events that underlie this process but also to possess the tools to manipulate these events in a spatial and temporal fashion both in and out of the cell. Today, a detailed mechanistic understanding of protein aggregation and amyloid formation in vitro and in vivo presents several challenges that remain to be addressed: (1) the difficulty associated with the expression or chemical synthesis of many amyloid-forming peptides and proteins, for example, amyloid- $\beta(A \beta)$, islet amyloid polypeptide (IAPP), and polyglutamine peptides and proteins; (2) the lack of molecular tools to control the initiation or reversal of protein misfolding and aggregation; (3) the complexity and variability of the misfolding and aggregation reactions; (4) the difficulties associated with structural characterization of the aggregates along the amyloid pathway due to their reduced solubility, instability, and heterogeneity; (5) the lack of molecular probes that enable the detection and quantification of different intermediates on the amyloid pathway; and (6) the difficulties associated with real-time monitoring of posttranslational modifications (PTMs), protein folding, and early oligomerization events in living cell. Therefore, new tools and improved experimental approaches that enable the characterization, monitoring, and manipulation of protein folding and self-assembly are required to address these challenges and to gain a molecular-level understanding of these processes and their impact on health and disease.

The past decade has witnessed great advances in the development of new fluorescent probes, imaging tools that enabled the visualization and tracking of molecular events, and biological processes in living systems. Combining these advances with the ability to incorporate unnatural amino acids and to introduce new chemistry into proteins through chemical and semisynthetic strategies presents unique opportunities for specific and selective modifications of protein sequence, structure, and function. In some cases, this allows one to obtain remote control over cellular processes and machinery with spatiotemporal resolution.

This review is primarily dedicated in highlighting recent results that illustrate how advances in chemistry and chemical biology have been and can be used to address some of the technical challenges discussed above. Although the majority of the studies reviewed here have focused on strategies to facilitate the synthesis of difficult sequences, improve peptide solubility, and control or inhibit the aggregation of amyloid peptides (A $\beta$, IAPP, and short amyloidogenic sequences), we also present recent results from our group and others that illustrate how several of the chemical tools that have been developed for these purposes can be used to provide novel mechanistic insight into the molecular mechanisms of amyloid formation, toxicity, and clearance. Furthermore, we include examples that demonstrate how the existing technologies for the chemical synthesis and semisynthesis of proteins are providing unique opportunities for extending the application of novel chemical tools and approaches to elucidate the sequence and molecular determinants of protein folding and aggregation and for understanding how naturally occurring and disease-associated modifications influence these processes. It is our hope that this 
review will stimulate further research in this area and catalyze increased collaboration at the interface of chemistry and biology to decipher the mechanisms and roles of protein folding, misfolding, and aggregation in health and disease.

\section{Chemical Tools to Facilitate the Synthesis and Purification of Amyloid-Forming Proteins}

Uncovering the mechanisms underlying the pathological role of amyloid-forming proteins and peptides in neurodegenerative diseases relies on their preparation or isolation in a pure and defined aggregation state. However, the preparation of amyloid-forming proteins by chemical means represents a significant challenge due to the tendency of these hydrophobic proteins to aggregate during synthesis and purification. The formation of secondary structures, in particular, $\beta$-sheet aggregates, is paralleled by a significant decrease in the coupling efficiencies and water solubility of peptide chains, rendering amyloid-forming proteins "difficult sequences" to access by chemical synthesis. ${ }^{1-6}$ Furthermore, aggregation-prone peptides and proteins, such as $A \beta 42$, exhibit broad elution profiles during reversed-phase HPLC purifications, which further hinders their isolation in sufficient yields. Nonetheless, several synthetic strategies have been developed to inhibit aggregation and enhance the water solubility of difficult sequences to markedly improve yields, water solubility, and handling. In the following section, we will give an overview of backbone and side-chain modifications that have been applied to either permanently or reversibly inhibit backbone hydrogen bonding, aggregation, and secondarystructure formation for the preparation and characterization of amyloid-forming proteins.

\section{Backbone N-Methylation, Esterification, and Olefination}

\section{Backbone N-methylation}

Backbone N-methylation has been shown to enhance the water solubility of synthetic amyloidforming proteins and peptides. Replacing the backbone amide protons with methyl groups effectively inhibits the formation of intermolecular hydrogen bonds required for peptide oligomerization into $\beta$-sheet aggregates (Fig. 1). Furthermore, the association of $\beta$-strands in an oligomerizing $\beta$-sheet may be further blocked due to steric hindrance imposed by the methyl substituents (Fig. 1). N-Methyl amino acids are commercially available building blocks that can be introduced into peptides using standard solid-phase synthesis protocols. However, they often require stronger coupling agents such as HATU and TBTU for their introduction into polypeptides. ${ }^{7}$ The resulting water-soluble and monomeric versions of the sequence will certainly aid in purification and handling. However, the disaggregating influence of $\mathrm{N}$-methylated residues on coupling efficiencies may be counterbalanced by the more difficult coupling to hindered secondary amines. In addition, while backbone N-methylation minimally perturbs peptide structure, it is an irreversible modification that eliminates the possibility of recovering the native form following synthesis and purification to investigate the structure and biological activity of amyloid-forming proteins. Instead, N-methylated derivatives of amyloid-forming proteins are often employed to disassemble aggregates and fibrils of their corresponding native sequences and thus have been proposed as potential therapeutic agents. ${ }^{7-12}$

The incorporation of $\mathrm{N}$-methylated amino acids has been shown to substantially enhance the water solubility and prevent the aggregation of both $A \beta$ and IAPP. By introducing N-methylated amino acids at alternate residues of the fibril-forming fragment $A \beta_{16-22}$, Gordon et al. demonstrated a 20-fold enhancement in water solubility compared with the nonmethylated version of the sequence. ${ }^{7}$ The methylated fragment of $A \beta_{16-22}$ exhibited a monomeric $\beta$-sheet conformation and acted as an inhibitor of $A \beta 40$ fibrillogenesis. ${ }^{7}$ The same group later showed that full-length $A \beta 40$ methylated at positions 17, 19,37, and 39 was highly water soluble and remained monomeric indefinitely, even at concentrations greater than $1 \mathrm{mM} .{ }^{13}$ This treatment was proposed to block $\beta$-sheet propagation at both $\mathrm{N}$ - and C-terminal strands of the $\beta$-hairpin-like structure of $A \beta$. Similarly, the introduction of a single N-methylated residue at various positions in the fibril-forming fragment $A \beta$ (25-35) generated soluble and nontoxic versions of the peptide, which were also able to inhibit the aggregation and toxicity of the wild-type fragment. ${ }^{10}$ More recently, hexapeptides derived from A $\beta$ C-terminal residues 32-37 methylated at multiple positions were soluble and nontoxic and were shown to inhibit the aggregation and toxicity of full-length $A \beta 40$ and $A \beta 42 .{ }^{9}$

N-Methylation of at least two residues of the minimum-length fibril-forming sequence of IAPP, IAPP (22-27), was sufficient to block $\beta$-structure, fibril formation, and peptide toxicity, as demonstrated by Kapurniotu et al. ${ }^{8}$ The N-methylated amino acids were incorporated in an $i, i+2$ arrangement such that lateral $\beta$-sheet extension via hydrogen bonding was blocked on one face of the peptide. The same group later used this approach to generate a non-amyloidogenic derivative of full-length IAPP doubly N-methylated at residues G-24 and I-26 with a 100-fold increase in water solubility compared 


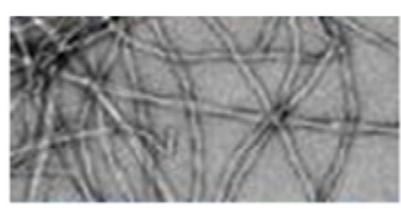

Permanent Modifications

\section{1 \\ Temporary Modifications}<smiles>[Z]C(=O)N(C)C([R])C(=O)NC([R])C(=O)N(C)C([R])C(=O)NC</smiles>

N-methylation<smiles>[R]C(NCC)C(=O)NC([R])C(=O)NC([R])C([R])C(C)=O</smiles>

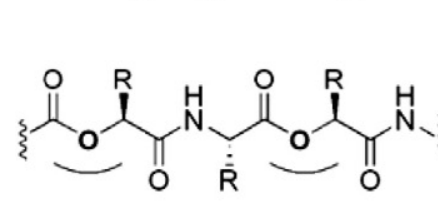

\section{Esterification}
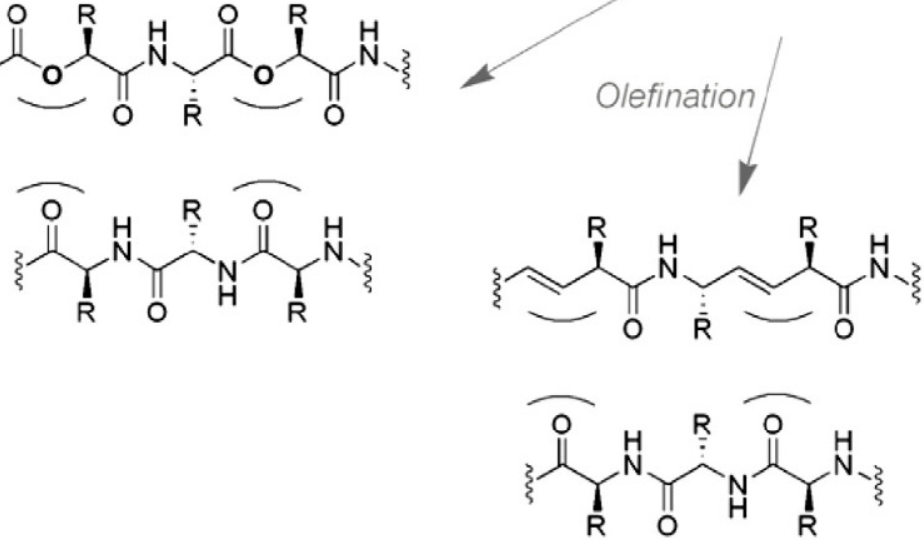
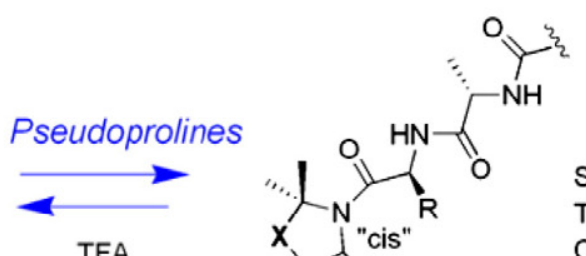

TFA

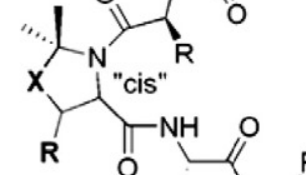

$\operatorname{Ser}\left(\Psi^{\mathrm{Me}, \mathrm{Me}}\right.$ pro $): \mathbf{X}=\mathrm{O} ; \mathbf{R}=\mathrm{H}$ $\operatorname{Thr}\left({ }^{\prime M e}{ }^{M e}\right.$ pro): $\mathbf{X}=0 ; \mathbf{R}=\mathrm{Me}$ Cys $\left(\Psi^{\mathrm{Me}, \mathrm{Me}}\right.$ pro): $\mathbf{X}=\mathrm{S} ; \mathbf{R}=\mathrm{H}$

Fig. 1. Schematic depiction illustrating the range of peptide modifications that have been introduced to reduce aggregation and facilitate the synthesis and purification of amyloid-forming peptides. Left: Irreversible backbone modifications that prevent peptide backbone hydrogen bonding, including methylation, esterification, and olefination. Right: Temporary (reversible) secondary-structure-disrupting side-chain modifications including pseudoprolines that can be removed by TFA treatment and $O$-acyl and $S$-acyl isopeptides that are reverted to native peptide backbones by controlled protecting group (Y) cleavage. 
with the wild-type protein. ${ }^{11}$ Although doubly Nmethylated IAPP did adopt a $\beta$-sheet structure as a result of backbone constraints introduced by the $\mathrm{N}$ methyl substituents, it did not aggregate into fibrillar structures.

\section{Backbone esterification and olefination}

Replacement of the peptide backbone amide by an ester group at selected residues of amyloidforming proteins has also been used to disrupt hydrogen bonding and formation of $\beta$-sheet aggregates (Fig. 1). Ester bonds lack the amide proton hydrogen bond donor involved in $\beta$-sheet oligomerization. Backbone esterification may have some advantages over backbone $\mathrm{N}$-methylation. The ester bond shares structural similarities with amide bonds, such as bond lengths and angles, and may be a more conservative modification, whereas $\mathrm{N}$-methylation often restricts peptides into $\beta$-structures. ${ }^{7,14}$ However, esterified peptides suffer from backbone hydrolysis, even at neutral $\mathrm{pH} .{ }^{14}$ Esterified peptides can be generated by solid-phase peptide synthesis (SPPS) using $\alpha$-hydroxy acid building blocks. As with N-methylation, backbone esterification is irreversible, which preclude the study of the biological activity of the unmodified protein.

Gordon et al. introduced ester bonds in A $\beta$ (16-20) in an $i, i+2$ arrangement such that one face of the peptide had normal hydrogen bonding capacity and one face lacked amide protons for hydrogen bonding. ${ }^{14}$ In contrast to the fibril-forming wild-type fragment, analytical ultracentrifugation measurements showed that the esterified $A \beta$ (16-20) remained predominantly monomeric. In another study, several derivatives of $A \beta 40$ esterified at a single position aggregated faster than the wild-type protein. ${ }^{15}$ All of the esterified peptides in this study exhibited $\beta$-sheet structure and eventually formed mature fibrils. Only esterification at F19 within the hydrophobic region of the protein was sufficient to slow aggregation kinetics and exhibited an extended lag phase. ${ }^{15}$

Bieschke et al. and Fu et al. incorporated an E-olefin substitution at the F19-F20 amide bond in the hydrophobic core of $A \beta$ to block both the hydrogenbond-donating and the hydrogen-bond-accepting capabilities of the peptide bond (Fig. 1). 15,16 Backbone olefination of the single peptide bond was sufficient to preclude fibril nucleation and growth in the modified peptide, but self-assembly into thioflavin $\mathrm{T}$ (ThT)-binding spherical aggregates was still observed.

\section{Pseudoproline dipeptides}

The introduction of Ser, Thr, or Cys residues temporarily protected as proline-like cyclic oxazolidine or thiazolidine structures offers a means of mimicking the denaturing influence of Pro residues on secondary structures (Fig. 1). ${ }^{17}$ These amino acid derivatives are termed pseudoprolines ( $\psi$ Pro) and induce a conformational "kink" in the peptide backbone due to a cis amide bond, which prevents peptide aggregation and $\beta$-structure formation, thus considerably improving the solvation and coupling efficiencies of difficult sequences. Pseudoprolines are typically introduced into a peptide chain as commercially available Fmoc-protected dipeptides to optimize incorporation. They are compatible with standard Fmoc/tBu protection and are cleavable within minutes with $90 \%$ trifluoroacetic acid (TFA). ${ }^{17}$ The cleavage of the desired peptide from an acid-labile resin is then achieved by treatment with TFA, generating a deprotected peptide with Ser, Thr, or Cys reverting to their native forms. The incorporation of two pseudoproline dipeptides has been applied, for example, to achieve synthetic access to human IAPP in high yields, an otherwise intractable protein. ${ }^{1}$

Orthogonal side-chain protecting groups, such as Allyl and Alloc, which can be cleaved without interfering with $\psi$ Pro modifications, are required to preserve the disaggregating and solubilizing effect of pseudoprolines during purification. ${ }^{18}$ Furthermore, resins that can be cleaved by treatment with weak acid such as 1\% TFA or acetic acid are required to prevent cleavage of the $\psi$ Pro modification. Following purification, the native structure of the peptide can then be induced by cleavage of $\psi$ Pro with TFA, followed by $\mathrm{pH}$ adjustment to permit protein folding.

The reversible nature of pseudoproline modifications of peptides and proteins (Fig. 1) has been exploited as conformational "switch" elements to facilitate synthesis, handling, and purification in the protected state and to allow the induction of native peptide folding and misfolding upon controlled deprotection. ${ }^{18}$ As the most relevant example, Tuchscherer et al. incorporated a single pseudoproline dipeptide, Fmoc-Leu-Ser( $\psi^{\mathrm{Me}, \mathrm{Me}}$ Pro $)-\mathrm{OH}$, into an otherwise inaccessible fibril-forming model decapeptide (Ser-Leu $)_{5}{ }^{18}$ The peptide was cleaved from the resin with weak acid, generating an unstructured and highly water soluble peptide with an intact structure-disrupting $\psi$ Pro side-chain modification. The $\psi$ Pro was cleaved by strong acid treatment, and $\beta$-sheet structure and fibrillogenesis were induced by adjusting the solution $\mathrm{pH}$ to 7 . Although switch elements derived from $\psi$ Pro building blocks are valuable tools to control the initiation of protein misfolding for mechanistic in vitro investigations, the approach is not compatible with in vivo studies due to the requirement for TFA or other harshly acidic conditions for protecting group removal.

\section{O-Acyl and S-acyl isopeptides}

A novel chemical approach that has been applied to achieve synthetic access to amyloid-forming 
peptides relies on the temporary introduction of backbone modified $O$-acyl or S-acyl isopeptides, in which peptide elongation is continued by an ester linkage on the side chains of Ser or Thr, or by a thioester linkage on the side chain of Cys (Fig. 1). The introduction of $O$-acyl or $S$-acyl isopeptide units within a growing peptide chain conformationally decouples the peptide fragments, promoting structure disruption and suppressing self-assembly and thus enhancing coupling yields (Fig. 1). ${ }^{3,19-21}$ Peptides incorporating $O$-acyl or S-acyl linkages are termed "switch peptides"18,22 or "click peptides" ${ }^{2,23}$ due to their reversible nature that allows the controlled induction of $\mathrm{O} \rightarrow \mathrm{N}$ or $\mathrm{S} \rightarrow \mathrm{N}$ acyl migration to restore the native peptide backbone, as well as protein folding, aggregation, and biological activity (Fig. 1). More specifically, an orthogonal $\mathrm{N}(\mathbf{Y})$ protecting group is installed on the backbone amine of the $\mathrm{O}$-acyl or $\mathrm{S}$-acyl isopeptide unit, allowing the controlled triggering of $\mathrm{N}$-deprotection and $\mathrm{O} \rightarrow \mathrm{N}$ or $\mathrm{S} \rightarrow \mathrm{N}$ acyl migration (Fig. 1). A key advantage of $O$-acyl or $S$-acyl isopeptide units over pseudoproline building blocks is that they are stable following standard peptide cleavage methods with TFA and can thus further facilitate purification and handling beyond the synthesis stage. Furthermore, many $\mathrm{N}(\mathbf{Y})$ protecting groups have been explored, and a variety of triggering systems such as $\mathrm{pH}^{22-26}$ enzymes, ${ }^{27}$ reducing agents, ${ }^{28}$ and light ${ }^{29,30}$ have been developed for restoring the native peptide backbone, some of which are even compatible with in vivo studies (vide infra).

The classic $\mathrm{N}(\mathbf{Y})$ protecting group is a proton $\left(\mathrm{H}^{+}\right)$ conveniently introduced during peptide cleavage with TFA. The resulting ammonium ion not only enhances aqueous solubility but also diminishes nucleophilicity and amide bond formation. Subsequent adjustment to physiological $\mathrm{pH}$ increases the concentration of deprotonated amine and induces $\mathrm{O} \rightarrow \mathrm{N}$ acyl migration within seconds to minutes. ${ }^{2,25}$

The introduction of a $\mathrm{pH}$-switchable $\mathrm{O}$-acyl isopeptide unit $\left(\mathbf{Y}=\mathrm{H}^{+}\right)$at Ser26 of $\mathrm{A} \beta 42$ generated a variant of $A \beta 42$ with a 100 -fold increase in water solubility compared with the native sequence (Fig. 2). 2,32 This modification also led to a sharp peak in the HPLC trace of the acyl isopeptide, compared with the broad elution pattern observed with native $A \beta 42$, suggesting strong suppression of secondary structure and aggregation. Facile conversion to native $A \beta 42$ was achieved in approximately $10 \mathrm{~s}$ after adjustment to $\mathrm{pH} 7.4$ with phosphatebuffered saline. Structural studies demonstrated a persistent monomeric, random-coil conformation in the acyl isopeptide of $A \beta 42$ under acidic conditions and a shift to a $\beta$-sheet structure and development of ThT-active aggregates within hours following $\mathrm{pH}$ neutralization. ${ }^{23}$ Similarly, $A \beta 42$ (E22 $\left.\Delta\right)$, an $A \beta$ variant common in Japanese pedigrees with Alzheimer's dementia, was synthesized as a $\mathrm{pH}-$ switchable peptide with an $\mathrm{O}$-acyl isopeptide unit at Ser26 and exhibited high water solubility facilitating its purification and handling. Furthermore, circular dichroism revealed that the peptide exhibited a random-coil conformation in $0.1 \%$ TFA aqueous solution and shifted to a $\beta$-sheet conformation within $6 \mathrm{~h}$ upon dilution in $\mathrm{pH} 7.4$ buffer. $^{25}$

(a)
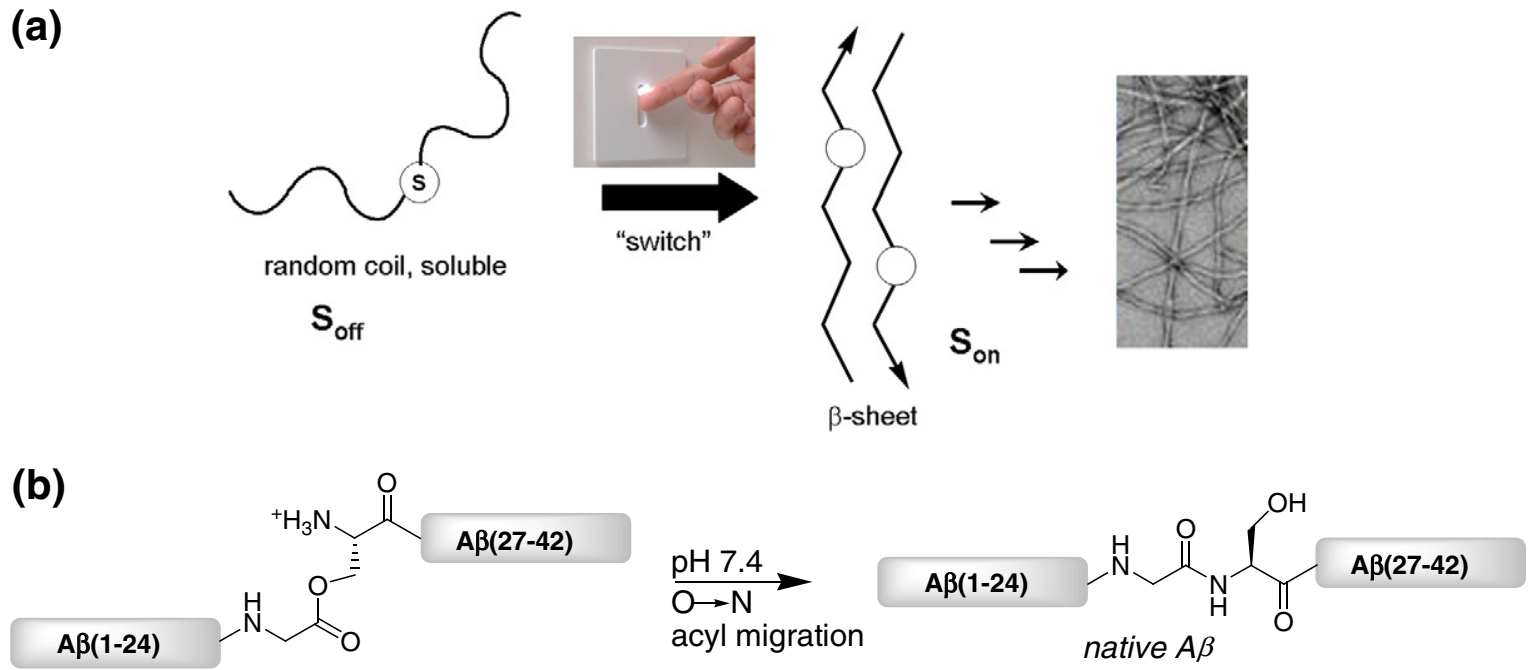

Fig. 2. Illustration of the switch concept as a mean of controlling the misfolding and aggregation of amyloid-forming polypeptides. (a) A switch element, S, disrupts normal backbone hydrogen bonding and conformationally decouples the peptide chain, promoting a monomeric and unstructured $\mathbf{S}_{\text {off }}$ state. A chemical or physical stimulus deactivates the switch element, allowing normal protein folding $\left(\mathbf{S}_{\mathbf{o n}}\right)$ and aggregation into fibrillar structures. (b) Introduction of the $O$-acyl isopeptide as a means to improve the synthesis of $A \beta 42$ and control its aggregation. Chemical structure of the Ser26 $O$-acyl $\mathrm{A} \beta 42$ isopeptide. Ser26 $\mathrm{O}$-acyl isopeptide of $\mathrm{A} \beta 42$ with $\mathrm{pH}$-triggered $\mathrm{O} \rightarrow \mathrm{N}$ acyl migration to restore native $\mathrm{A} \beta$. $^{2,23}$ 


\section{O-Acyl Isopeptide Molecular Switches as Tools to Control Amyloid Protein Folding, Self-Assembly, and Disassembly}

The uncontrolled polymerization of $\beta$-sheet structures of amyloid-forming peptides is one of the main obstacles in elucidating their toxic and pathologic mechanisms in vitro and in vivo. Reversible manipulation of the peptide backbone with a molecular switch element, S, may be employed to retain the amyloid-forming peptide in a soluble, typically monomeric state (Fig. 1). Controlled release of the switch element with a known chemical or physical stimulus restores the native peptide structure and triggers protein misfolding, self-assembly, and amyloid fibril formation (Fig. 1). The underlying mechanisms involved in amyloid protein toxicity may then be probed at the onset of misfolding and aggregation with structural investigations and biological activity experiments. ${ }^{33}$ Investigations using this approach have already contributed valuable insight into the initial kinetics of amyloid formation ${ }^{22}$ and allowed the identification of specific aggregation "hot spots" 27 and antiamyloid agents. ${ }^{31}$ Remarkably, switch peptides have also been adapted to control the reverse process of amyloid formation, namely, the conversion of developed fibrillar aggregates into monomeric units. ${ }^{24}$ Here, we review recent results using switch peptides to control and understand the mechanisms of amyloid fibril formation, disassembly, and inhibition. We also highlight the advantages of light-activated switchable groups and the potential to introduce switchable elements into full-length amyloid-forming proteins for mechanistic investigations.

\section{Switch peptides based on $\mathrm{X} \rightarrow \mathrm{N}$ acyl migration to control conformational transitions in amyloid-forming proteins}

Peptides with reversible $O$-acyl or $S$-acyl isopeptide modifications (Fig. 1) have also been applied beyond the synthesis and purification stage as switch elements to achieve control over protein structure and self-assembly for structural and mechanistic studies of amyloid-forming proteins in vitro. Switch peptides based on $\mathrm{O} \rightarrow \mathrm{N}$ or $\mathrm{S} \rightarrow \mathrm{N}$ acyl migrations are perhaps the best-studied systems for controlling the onset of misfolding and fibril formation in peptides and proteins involved in neurodegeneration. ${ }^{18,22,27,34}$ Many switch peptides based on $\mathrm{X} \rightarrow \mathrm{N}$ acyl migrations ( $\mathrm{X}=\mathrm{O}$ or $\mathrm{S}$ ) use the isopeptide switch element $\mathbf{S}$ to conformationally decouple a structural nucleation unit $(\sigma)$ from the target peptide (P) (Fig. 3). ${ }^{18,22}$ Triggering of $\mathrm{X} \rightarrow \mathrm{N}$ acyl migration via selective $\mathrm{Y}$ protecting group cleavage establishes the regular peptide bond between the $\sigma$ unit and $\mathbf{P}$, causing the structure to shift from one state $\left(\mathbf{S}_{\text {off }}\right)$ to another defined state $\left(\mathbf{S}_{\text {on }}\right)$ dictated by the conformational preference of $\sigma$ (Fig. 3). One advantageous feature of switch peptides based on $X \rightarrow N$ acyl migration is their rapid response: $Y$ protecting group removal rapidly establishes the native peptide bond and the desired conformational transition within seconds to minutes. ${ }^{22,29,30}$ Another distinct advantage of these

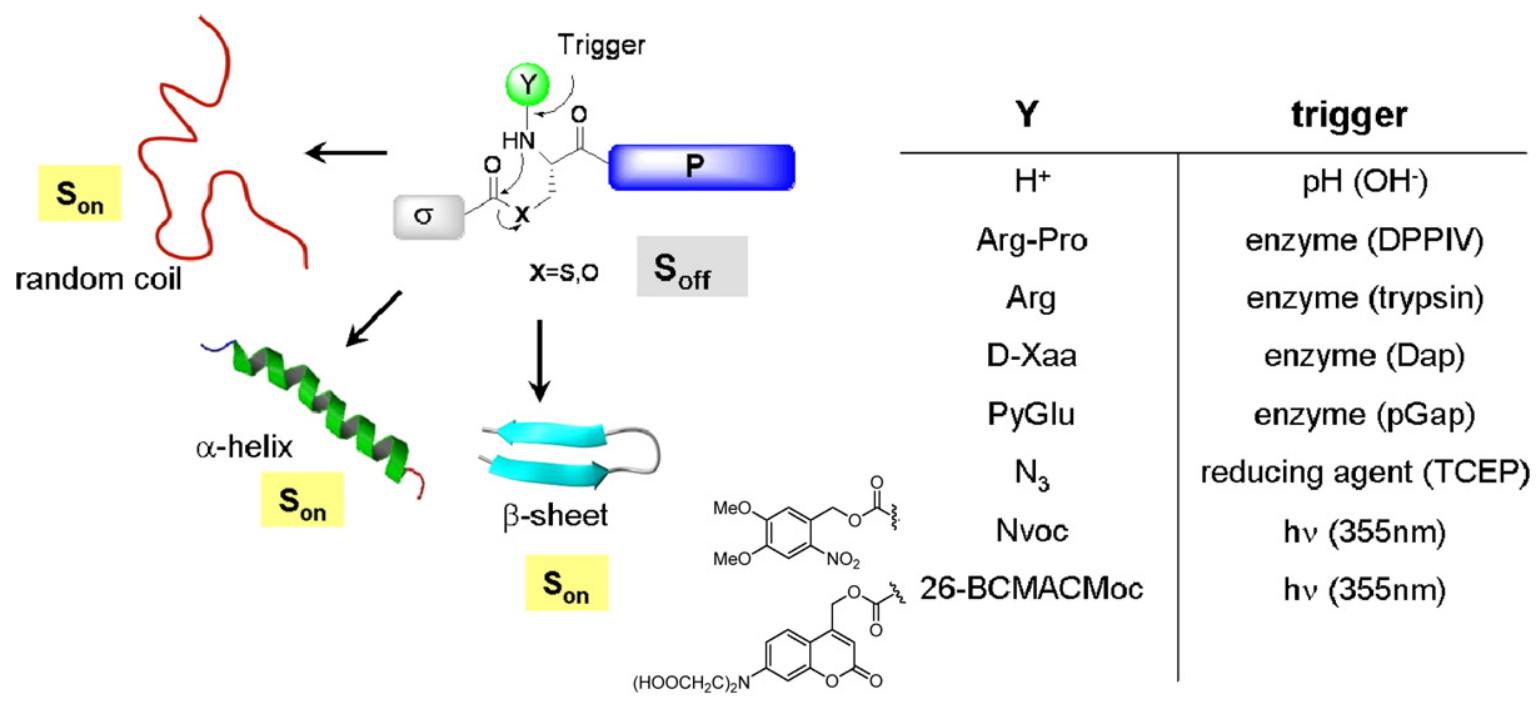

Fig. 3. Switch peptides as folding precursors and means to study controlled conformational transitions. Triggering of $\mathrm{X} \rightarrow \mathrm{N}$ acyl migrations via $\mathrm{Y}$ protecting group cleavage leads to a regular peptide bond between the structural induction unit $(\sigma)$ and the peptide of interest $(\mathbf{P})$ converting the peptide from the $\mathbf{S}_{\text {off }}$ state to the $\mathbf{S}_{\text {on }}$ conformation dictated by $\sigma$. A table listing current triggering methodologies developed for $\mathbf{Y}$ protecting group removal is also shown. 
systems is the diverse choice of triggering methodologies that have been developed for inducing $\mathbf{Y}$ protecting group cleavage and conformational switching, including $\mathrm{pH}^{22,23,25}$ enzymatic cleavage, reducing agents, ${ }^{28}$ and light ${ }^{29,30}$ (Fig. 3). Given the inability to control and selectively regulate physiological $\mathrm{pH}$, redox potential, and enzymatic cleavage, photocleavage methods offer the most potential for spatiotemporal control over amyloidogenic protein and peptide conformations for in vivo mechanistic investigations (vide infra). In the following sections, we will highlight several applications of switch peptides based on $\mathrm{X} \rightarrow \mathrm{N}$ acyl migrations to manipulate the structure and aggregation of amyloidforming proteins to probe key mechanistic questions of protein misfolding and aggregation related to neurodegenerative diseases. Namely, we will demonstrate the use of switch peptides to identify aggregation "hot spots", develop high-throughput screening assays to identify anti-amyloid agents, and study the reversibility of fibril formation.

\section{Switch peptides to reveal aggregation "hot spots" in amyloid-forming proteins}

The installation of multiple consecutive switch elements with orthogonal protecting $\mathrm{N}(\mathbf{Y})$ protecting groups has provided a method to identify aggregation "hot spots" within the sequences of amyloidforming proteins and peptides. ${ }^{27} \mathrm{~A}$ classic example is the introduction of two S elements in A $\beta 42$ with a $\mathrm{pH}$-cleavable $\mathbf{S}_{\mathbf{1}}$ element at Ser26 and an enzymecleavable $\mathbf{S}_{2}$ element at Ser37 (Fig. 4a). ${ }^{27}$ The pHinduced acyl migration at $\mathbf{S}_{\mathbf{1}}$ occurred within minutes. However, the conformational transition to a $\beta$-sheet and fibril formation was only observed upon subsequent enzyme-induced acyl migration by treatment with dipeptidyl peptidase IV at switch element $\boldsymbol{S}_{2}$, supporting the impact of the hydrophobic $C$-terminus on $A \beta 42$ misfolding and aggregation (Fig. 4a).

\section{Controlling the initiation of amyloid protein misfolding and self-assembly}

The insertion of an $\mathrm{O}$-acyl isopeptide switch element S at Ser26 of A 342 and certain diseaseassociated derivatives has been employed not only to enhance solubility and prevent aggregation for synthetic purposes ${ }^{2,30}$ but also to control the onset of $A B$ misfolding, oligomerization, and fibril formation. ${ }^{23,25}$ Given the strong fibril-forming propensity of full-length $A \beta 42$, the attachment of nonnative fibril-inducing $\sigma$ elements is not necessary to direct fibril formation in this sequence. Wang et al. demonstrated a conformational shift from a persistent random coil $\left(\mathbf{S}_{\text {off }}\right)$ to $\beta$-sheet in disease-associated $A \beta(E 22 D)$ within $6 \mathrm{~h}$ following $\mathrm{pH}$-induced $\mathrm{O} \rightarrow \mathrm{N}$ acyl migration $\left(\mathbf{S}_{\mathbf{o n}}\right){ }^{25}$ Similar results were also obtained with the wild-type sequence following photo-triggered $\mathrm{O} \rightarrow \mathrm{N}$ acyl migration with a corresponding development of ThT-binding protein aggregates. ${ }^{23,30}$ The development of $\beta$-sheet aggregates of $\mathrm{A} \beta 42$ following $\mathrm{pH}$ triggered $\mathrm{O} \rightarrow \mathrm{N}$ acyl migration at Ser26 was also observed by dynamic light scattering and atomic force microscopy in a separate study. ${ }^{35}$ The main advantage of these systems is that they permit the evaluation and characterization of the early stages and kinetics of misfolding, aggregation, and fibril formation.

Fibril formation in shorter fragments of amyloidforming proteins has been investigated using fibrilforming $\sigma$ units. $^{22}$ The insertion of an O-acyl isopeptide switch element $\mathbf{S}$ between the fibrilforming (Ser-Leu) ${ }_{2}-\mathrm{A} \beta(14-20)$ induction unit $(\sigma)$ and the peptide sequence $A \beta(21-24)-S e r-L e u-G l y ~(P)$ generated a persistent monomeric random-coil derivative ( $\mathbf{S}_{\text {off }}$ state). Triggering of $\mathrm{O} \rightarrow \mathrm{N}$ acyl migration by raising the solution $\mathrm{pH}$ from 4.4 to 7 led to a concomitant shift to $\beta$-sheet structure within minutes and the development of fibrils within 2 days as imaged by transmission electron microscopy (TEM). ${ }^{22}$ Similarly, a fibril-forming Leu-SerLeu induction unit $(\sigma)$ was separated from the IAPP fragment NFGAIL by a pH-switchable O-acyl isopeptide switch element to control the transition from a random-coil $\mathbf{S}_{\text {off }}$ state to a $\beta$-sheet structure $\left(\mathbf{S}_{\text {on }}\right)$, which was paralleled by fibril formation in the sequence. $^{22}$

\section{Identification of anti-amyloid agents with switch peptides as model systems}

The inability to control spontaneous aggregation and fibril formation in amyloid-forming sequences has hindered the application of high-throughput screening assays to identify anti-amyloid agents that act at specific stages of aggregation. In particular, the development of chemical tools that control amyloid protein aggregation to allow the selection of inhibitors that block the initial stages of aggregation could have advantageous applications in medicine. Switch peptides, which typically exhibit enhanced synthetic accessibility and solubility compared with their native parent peptides, have been adapted as model systems for the identification of viable aggregation inhibitors of $A \beta$ target sequences. ${ }^{31}$ Mutter and co-workers introduced two switch elements at Ser residues flanking peptide $\mathrm{A} \beta$ (1424), a known fibril-forming $A \beta$ fragment (Fig. $4 b$ ). The sequence design also contained two flanking $\sigma$ elements to promote fibril formation in the $A \beta$ fragment following $\mathrm{O} \rightarrow \mathrm{N}$ acyl migration (Fig. 4b). In the absence of inhibitor, the model peptide converted into $\beta$-sheet fibrillar structures within $4.5 \mathrm{~h}$ following $\mathrm{pH}$-induced $\mathrm{O} \rightarrow \mathrm{N}$ acyl migration. Aggregation into fibril structures was slowed in the 
presence of known polyphenolic inhibitors of native $\mathrm{A} \beta$ such as tannic acid, myricetin, and dopamine (Fig. 4b), indicating that switch peptides offer relevant model systems for the screening of inhibitors of amyloid fibril formation.

To what extent is amyloid formation reversible: An application of the switch concept

Most efforts aimed at treating neurodegenerative diseases focus on the prevention of protein misfolding and aggregation, which is based on the assumption that developed amyloid fibrils occupy the global free-energy minimum relative to the native state of amyloid-forming proteins. ${ }^{36-38}$ Amyloidrelated diseases could also be treated by promoting dissociation and clearance of already developed amyloid fibrils. However, relatively little is known concerning the ability to induce the reverse process of fibril formation and to what extent fibrillar structures can be dissociated. Remarkably, an application of the switch concept has been employed by Mimna et al. to control the conformational conversion from developed insoluble fibrils with $\beta$-sheet structure into soluble $\alpha$-helical structures (Fig. 5). ${ }^{24} \mathrm{~A}$ switch peptide was designed with an $\alpha$ helix-nucleating N-cap Ac(cyclo-1-5)-KARAD containing an $i, i+4$ lactam bridge between Lys1 and Asp5 $(\sigma)$ separated from the fibril-forming $A \beta$ fragment $\mathrm{A} \beta$ (14-25) by a $\mathrm{pH}$-cleavable Ser-derived switch element $\mathbf{S}$ (Fig. 5). At $\mathrm{pH} 4.5$ in $25 \%$ trifluoroethanol, the peptide adopted a $\beta$-sheet structure due to conformational decoupling between $\mathrm{A} \beta$ (14-25) and the helix-nucleating sequence in the $\mathrm{S}_{\text {off }}$ state. Neutralization of the solution $\mathrm{pH}$ induced $\mathrm{O} \rightarrow \mathrm{N}$ acyl migration and an unprecedented conversion of $A \beta$ from a predominantly $\beta$-sheet structure to an $\alpha$-helix $\left(\mathbf{S}_{\text {on }}\right)$ within minutes, as demonstrated by circular dichroism. ${ }^{24}$ Remarkably, dissociation of fibrils in the switch peptide was observed by TEM within $12 \mathrm{~h}$ following the induction of $\mathrm{O} \rightarrow \mathrm{N}$ acyl migration in the sequence (Fig. 5). These results not only further emphasize the ability of well-designed switch peptides to control conformational transitions in proteins but also highlight the potential of enhancing fibril dissociation and clearance as an additional therapeutic strategy.

\section{Photocontrol of Peptide Aggregation and Potential for In Vivo Applications}

The use of light to control peptide conformation and aggregation is an appealing approach due to the highly selective nature of photocleavage methods, which typically do not disturb other aspects of the experimental system. ${ }^{39}$ In particular, for in vivo investigations, cellular components usually do not react with light, provided that the wavelengths used for photo-release are not too short. ${ }^{39}$ This is in clear contrast to other methods used to shift peptide conformational transitions, such as $\mathrm{pH}$ or redox potential, which can severely modify other components of a cellular system. Furthermore, advances in technology have enabled selected regions of a cellular sample to be irradiated with specific wavelengths, thus offering the potential for both spatial and temporal control over peptide conformational transitions and aggregation onset to determine the resulting effects on a biological system. Systems designed with photocleavable groups that block $\beta$-sheet structure and aggregation could thus provide valuable insights into the mechanisms underlying the cellular toxicity of amyloid-forming proteins at the onset of misfolding and aggregation. However, applications of photocleavable protecting groups to control the structure and assembly of amyloidogenic proteins have not yet been reported beyond the level of in vitro studies.

Taniguchi et al. introduced an $\mathrm{O}$-acyl isopeptide unit at Ser26 of $A \beta 42$ with a photocleavable $\mathrm{N}(\mathbf{Y})$ protecting group ( $\mathbf{Y}=$ Nvoc) (Fig. 3). ${ }^{29}$ Conversion from a persistent monomeric state to an oligomeric state following light-induced Nvoc protecting group cleavage was observed by size-exclusion chromatography. The same group later reported several other similar systems with synthetic coumarinderived photocleavable $\mathrm{N}(\mathrm{Y})$ protecting groups appended with water-solubilizing substituents to further enhance $A \beta$ solubility. ${ }^{30}$ In particular, the $Y$ protecting group 26-BCMACMoc (Fig. 3) enhanced the solubility of the switch peptide 100-fold over the native sequence; the switch peptide did not selfassemble until light-induced cleavage. ${ }^{30}$ Systems such as these could have valuable applications for the identification of the toxic function of $A \beta$ at the onset of misfolding and aggregation in vivo following light-induced $\mathrm{O} \rightarrow \mathrm{N}$ acyl transfer.

A novel system reported by Bosques and Imperiali introduced a photocleavable solubilizing cationic polymer based on $\mathrm{N}, \mathrm{N}$-dimethylethylenediamine (DMDA) on an N-terminal Asn residue linked to the fibril-forming human prion protein (PrP) fragment 174-195 (Fig. 6a). ${ }^{40}$ A photocleavable linker derived from 2-nitrophenyl propionic acid was introduced to separate the prion fragment from the solubilizing polymer. The DMDA polymer, or fibrilinhibitory unit, blocked fibril formation in the native sequence for $24 \mathrm{~h}$ (Fig. 6a). Photocleavage by irradiation at $365 \mathrm{~nm}$ for $15 \mathrm{~min}$ released the native peptide, yielding fibrils within $6 \mathrm{~h}$ (Fig. 6a). ${ }^{40}$ The commercial availability of the photolabile linker 3-amino-3-(2-nitrophenyl)-propionic acid, the ease of its incorporation into peptides by SPPS, and the plethora of other potential solubilizing units such as polyethylene glycol (PEG) or sugars indicate that these strategies could be widely adapted in 
(a)
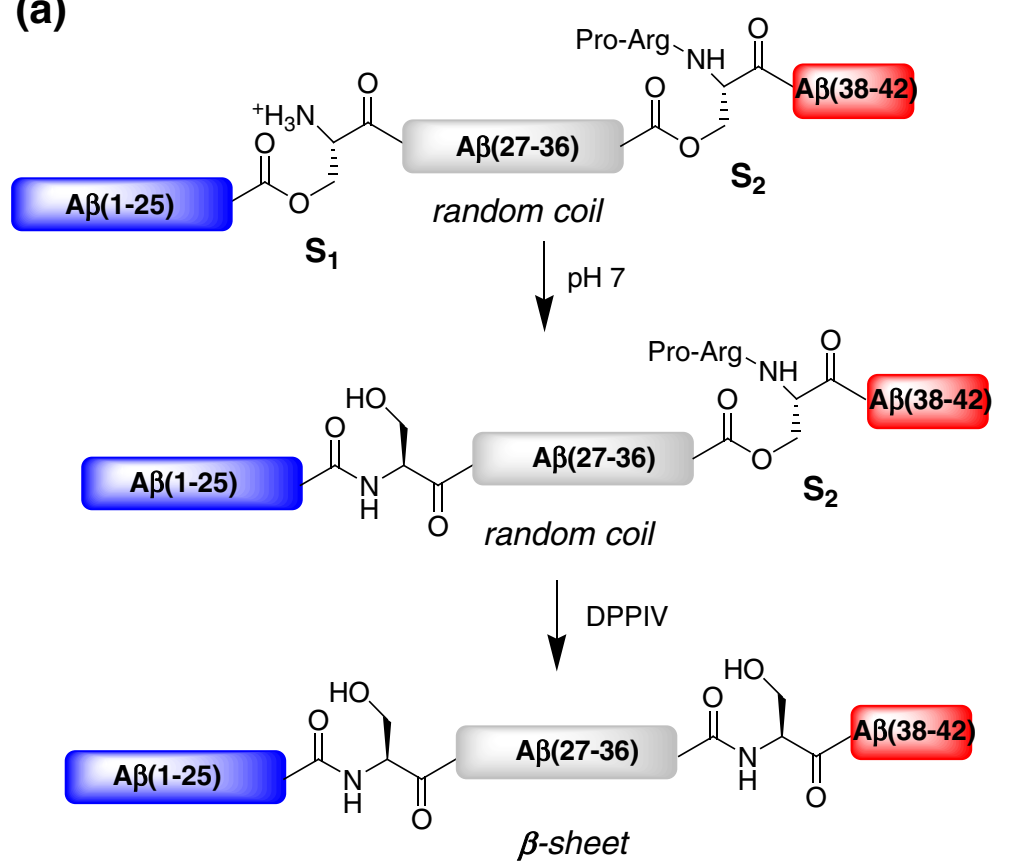

(b)
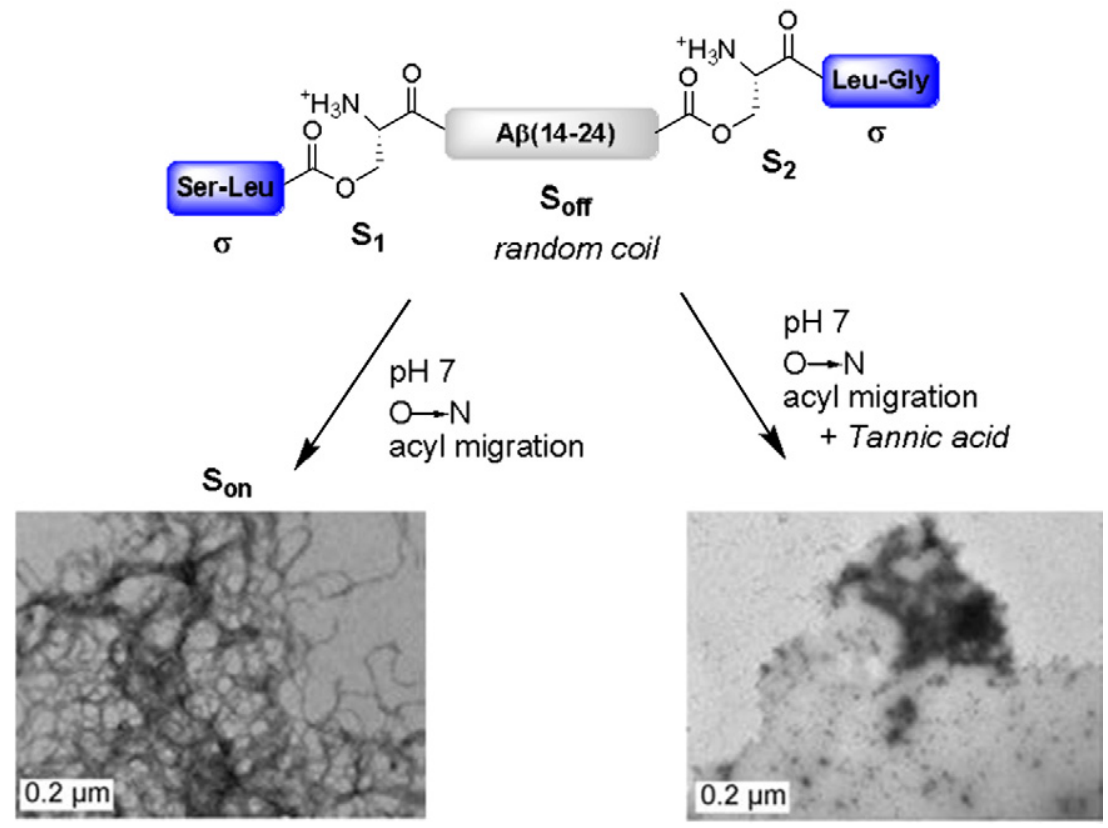

Fig. 4. Use of multiple switch elements to identify highly aggregation domains in A $\beta$ and to screen for aggregation inhibitors. (a) Multiple switch elements with orthogonal triggers to identify C-terminal $\mathrm{A} \beta$ (37-42) as an aggregation "hot spot"; ${ }^{27}$ (b) inhibition of fibril formation by tannic acid following $\mathrm{pH}$-induced acyl migration in a model switch peptide. ${ }^{31}$ TEM images reproduced from Camus et al. ${ }^{31}$ with permission. 

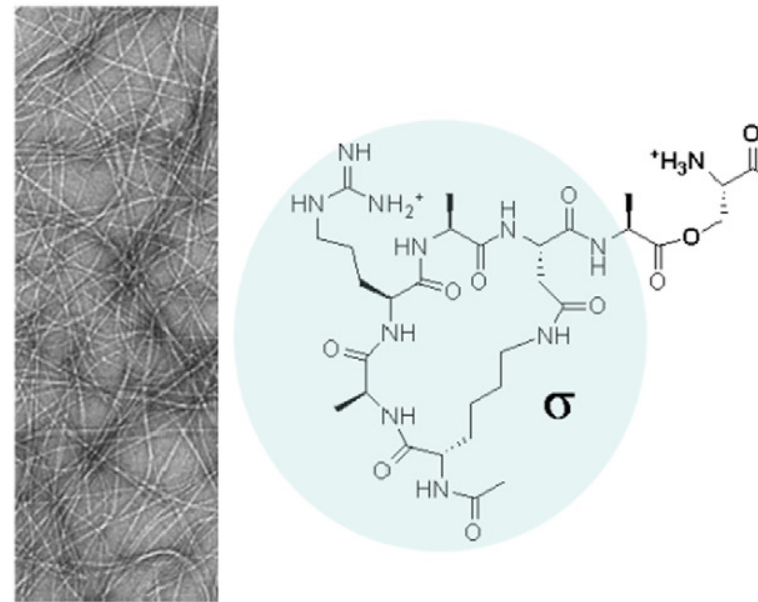

$S_{\text {off }}$

$\mathrm{O} \rightarrow \mathrm{N}$ acyl

migration

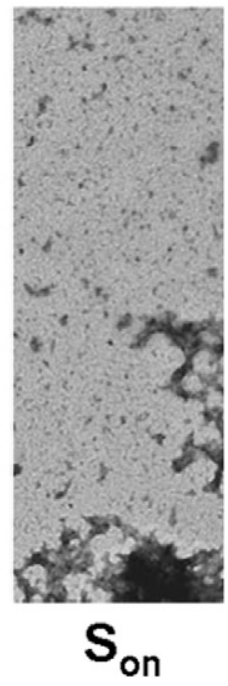

Fig. 5. Applying the switch concept to study the reversibility of amyloid fibril formation by AB (14-25). ${ }^{24}$ The activation of the helix-nucleating $\sigma$ element Ac(cyclo-15)-KARAD was used to disrupt and disassociate preformed fibrils of $\mathrm{A} \beta$ (14-25) into soluble $\alpha$-helices following $\mathrm{pH}$-induced $\mathrm{O} \rightarrow \mathrm{N}$ acyl migration. Reproduced from Ref. 24. 
(a)

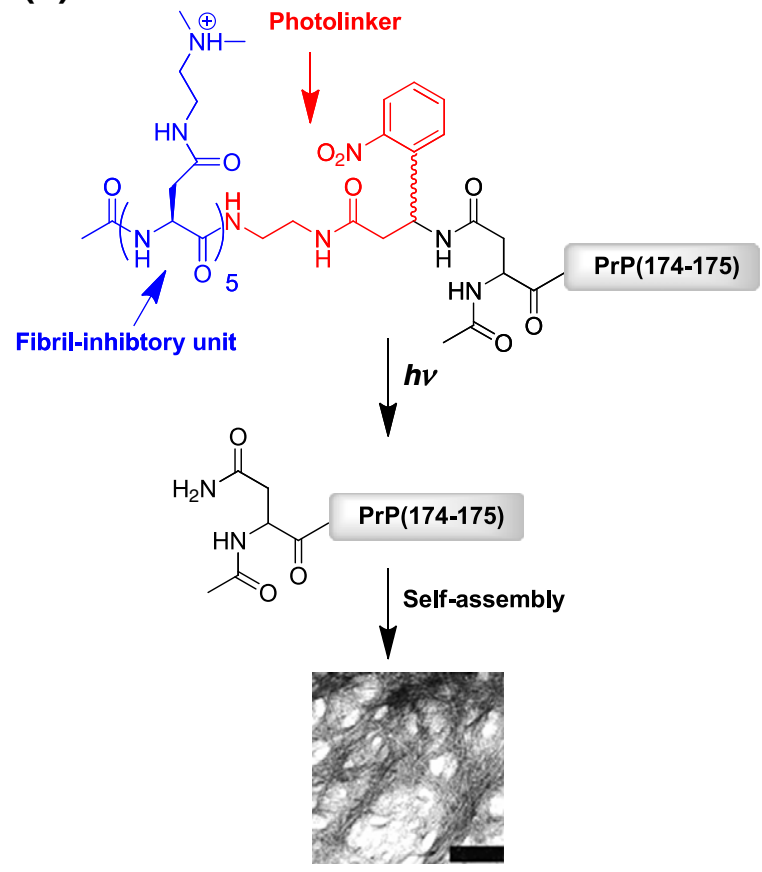

(b)

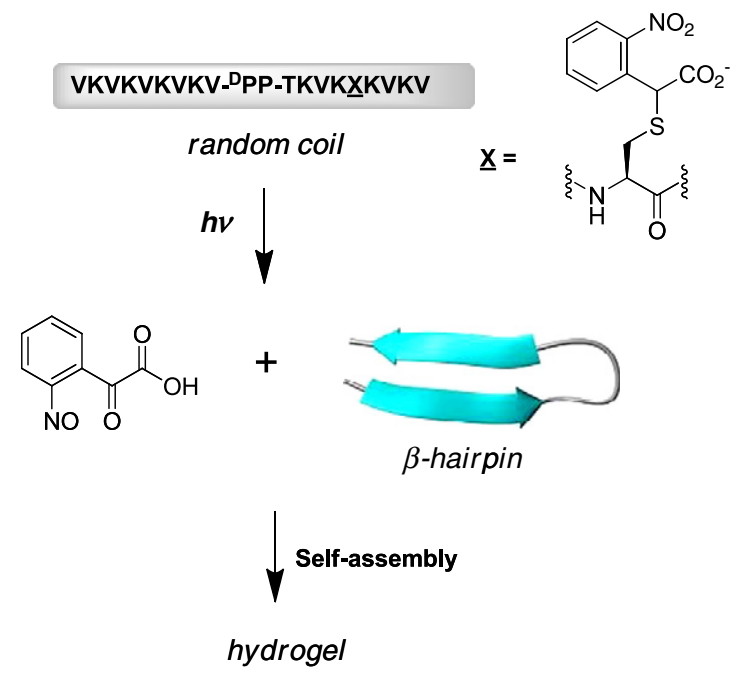

Fig. 6. Photocontrol of peptide aggregation. (a) Photolytic control of fibril formation by the human prion protein fragment $\operatorname{PrP}(174-195) .{ }^{40}$ A DMDA cationic polymer (fibril-inhibitory unit and solubilizing domain) was attached to the side chain on an N-terminal Asn residue of the prion fragment by a photocleavable linker derived from 2-nitrophenyl propionic acid. Light irradiation was used to induce cleavage of the solubilizing polymer, release of the native sequence, and subsequent fibrillization of $\operatorname{PrP}(174-195)$. TEM image reproduced from Ref. 40; bar size $=200 \mathrm{~nm}$. (b) Light-induced cleavage of a photocaged Cys residue allowed $\beta$-hairpin formation and self-assembly into hydrogel structures in a designed peptide. ${ }^{41}$

controlling fibril formation in other amyloid-forming sequences.

Other systems have been designed using light to control the self-assembly of non-amyloid-forming designed peptides into $\beta$-sheet aggregates, hydrogels, ${ }^{4}$ and even fibrillar structures. ${ }^{42}$ The following relevant and well-designed systems could also be applied toward achieving spatiotemporal control over amyloid fibril formation using light and possibly to unravel their toxic mechanisms in vivo. Haines et al. employed a photocleavable $\alpha$-carboxyl2-nitrobenzyl (CNB) protection on a Cys residue to block $\beta$-hairpin formation and self-assembly in a Val-Lys-based designed $\beta$-hairpin peptide with a ${ }^{D}$ Pro-Pro turn nucleator (Fig. 6b). ${ }^{41}$ The charged CNB protecting group blocked intramolecular hydrophobic association of the Val-rich face of the hairpin, maintaining the peptide in a random-coil conformation and blocking intermolecular facial self-assembly into polymeric $\beta$-sheet networks. ${ }^{41}$ UV irradiation of the peptide for $30 \mathrm{~min}$ released the caged Cys side chain, resulting in a $\beta$-sheet signature in the circular dichroism spectrum and rigid hydrogel formation in the sequence (Fig. 6b). Recently, a photocleavable 2-nitrobenzyl group was introduced on the backbone of a bioactive peptide amphiphile containing the sequence Arg-Gly-AlaSer. ${ }^{42}$ Photocleavage shifted the structure from spherical aggregates into fiber-like structures, as imaged by TEM. ${ }^{42}$

\section{Photoinduced Cross-Linking as a Tool to Study Amyloid Oligomer and Fibril Assembly}

Despite mounting evidence suggesting that lowmolecular-weight (LMW) oligomeric species (e.g., dimers, trimers, and nmers) are the primary toxic forms of $A \beta$ in $A D$, a detailed characterization of the chemical and structural properties of many of these oligomers is lacking, mainly due to their instability and rapid conversion into higher-order aggregates and amyloid fibrils. While many of the tools described above provide excellent means for controlling the initiation of folding and assembly, there is still a need for novel tools and approaches that enable detection of early oligomerization events and the characterization of putative toxic 
oligomers. In this section, we will review the use of specific chemical cross-linking strategies to trap, detect, and characterize LMW oligomers in the amyloid pathway.

Chemical cross-linking of proteins and protein complexes using bifunctional reactive probes often suffers from low yields of covalently captured complexes and requires long reaction times $(30 \mathrm{~min}$ to several hours). ${ }^{43}$ Moreover, moderately reactive agents (often amine directed, in N-hydroxysuccinimideactivated carboxylic acids) require the use of large excesses, resulting in widespread modification of lysine residues on protein surfaces and thus potentially creating artifacts by perturbing the complexes under study. Rapid reaction times and high yields are required to capture transient, metastable oligomeric species, such as early assembly states on the pathway to amyloid formation. These characteristics are achieved by inert photo-activated precursors, the photolysis of which rapidly generates highly reactive groups in situ (either radicals, ${ }^{43}$ carbenes, or nitrenes), which quickly react with neighboring residues in an intramolecular or intermolecular fashion. Two broad strategies for the use of such photoinduced crosslinkers are discussed below: (i) the introduction of photoactivatable groups as unnatural amino acids in peptides and proteins and (ii) photoinduced protein cross-linking of unmodified proteins (PICUP), which uses a free, soluble probe. In the context of amyloid research, both of these approaches have been used to study protein-protein interactions between amyloids and other cellular proteins and to map interchain interactions during oligomer assembly.

\section{Photoreactive unnatural amino acids}

Amino acid derivatives bearing light-inducible cross-linking probes can be inserted in peptide or protein sequences by chemical or genetic methods. ${ }^{44,45}$ The most widely used chemical modifications include benzophenones, aryl azides (as phenylalanine and tyrosine analogues), and diazirines (which can be incorporated in amino acids to mimic methionine, leucine, isoleucine, or phenylalanine). Recently, a novel probe containing the trifluoromethyldiazirine (tfmd) moiety was developed by Smith et al. to study the packing of $\beta$-strands in $A \beta$ fibrils. ${ }^{46}$ The photo-inducible group, which generates a very reactive carbene upon irradiation at $\sim 350 \mathrm{~nm}$ (Fig. 7a), was placed on a phenylalanine side chain (tfmd-Phe) within the model peptide $A \beta_{16-22}$ (sequence: $N^{\alpha}$-acetyl-KLVFFAE-amide), which correspond to the central hydrophobic fragment of $A \beta$ and that had been shown to form amyloid fibrils. ${ }^{50}$ Negative-staining TEM showed that replacing Phe4 by tfmd-Phe did not alter the fibrillization of the tfmd-containing peptide $\left(A \beta^{*}{ }_{16-22}\right)$ compared to the unmodified peptide $\left(A \beta_{16-22}\right)$ (Fig. $\left.7 b\right)$. Fibrils of $A \beta{ }_{16-22}$ were irradiated for $1 \mathrm{~h}$ to induce cross- linking and were subsequently fully dissociated in hexafluoroisopropanol, thus disrupting any noncovalent interactions but leaving cross-linked species intact. The peptides were then analyzed by electrospray ionization-ion mobility spectrometry-tandem mass spectrometry to map inter- and intra-monomer cross-links. The use of ion mobility spectrometry permitted the separation of cross-linked species from monomeric ones (containing either intramolecular cross-link in which the reactive carbene had been quenched). Interestingly, only dimeric species were observed when inter-peptide cross-links were detected. These results are consistent with a model in which tfmd-Phe residues are arranged in an offset stacked fashion (stabilized by $\pi-\pi$ interactions) within antiparallel $\beta$-sheets, at sites where no hydrogen bonds are directly flanking the paired residues (Fig. $7 \mathrm{c}$, top), rather than with the other possible organization of tfmd-Phe (face-to-edge panel; Fig. 7c, bottom). In the latter model, one of the tfmd groups is directed toward peptides located in the plane "above", and cross-linking would be expected to generate higher-order species (timers, tetramers, and ongoing). The observation of dimers only essentially rules out that model.

The method developed by Smith et al. enables the stabilization of transient oligomers and the characterization of the arrangement of specific residues within different oligomeric intermediates on the pathway to amyloid fibrils. More detailed information on the placement of other residues can be obtained in a similar way by taking advantage of the diazirine-containing probes developed by Suchanek et al., ${ }^{51}$ which can mimic leucine, isoleucine, and methionine residues. Such studies could also be extended to the more relevant full-length $A \beta$ and amyloidogenic peptide using microwave-assisted SPPS, which was recently shown to enable the chemical synthesis of $A \beta_{1-42}$ in high yields $(78 \%){ }^{52}$ The incorporation of multiple photo-inducible crosslinkers within amyloid peptides and proteins could also be used to stabilize entire transient assemblies for detailed mechanistic studies. Photocross-linking residues have also been introduced in proteins by the nonsense suppression method developed by Wang and Schultz. ${ }^{53}$ However, this method has not yet been applied to amyloidogenic proteins.

\section{Photoinduced cross-linking of unmodified proteins}

The incorporation of photoreactive probes within peptides and proteins is not always possible (e.g., because of the synthetic challenges associated with preparing amyloid proteins and because many of the unnatural amino acids either are not commercially available or are prohibitively expensive). Such modifications may also be undesirable when it is suspected that they could interfere with 
(a)<smiles>CCc1ccc(C2(C(F)(F)F)N=N2)cc1</smiles>

(b)

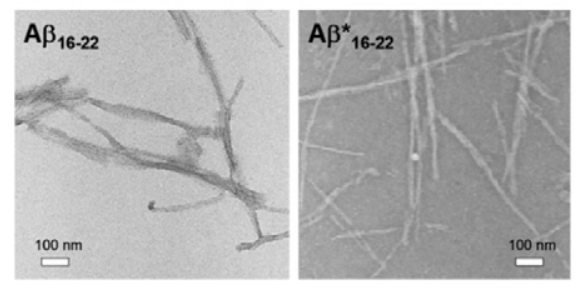

(c)

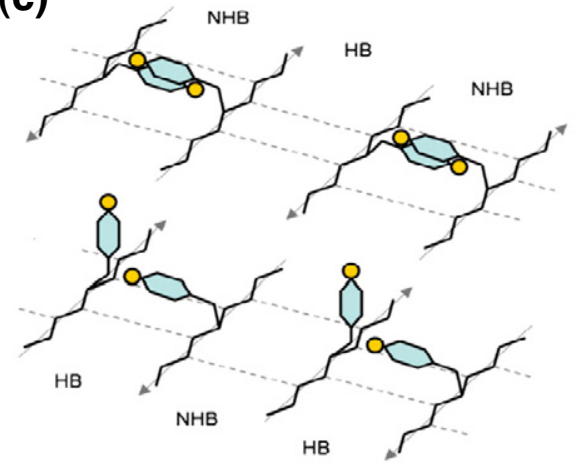

(d)

(e)

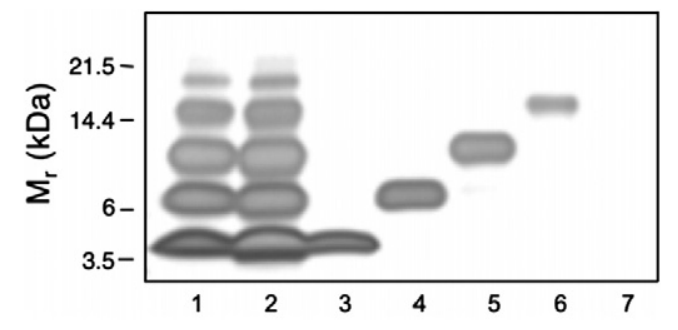

(f)

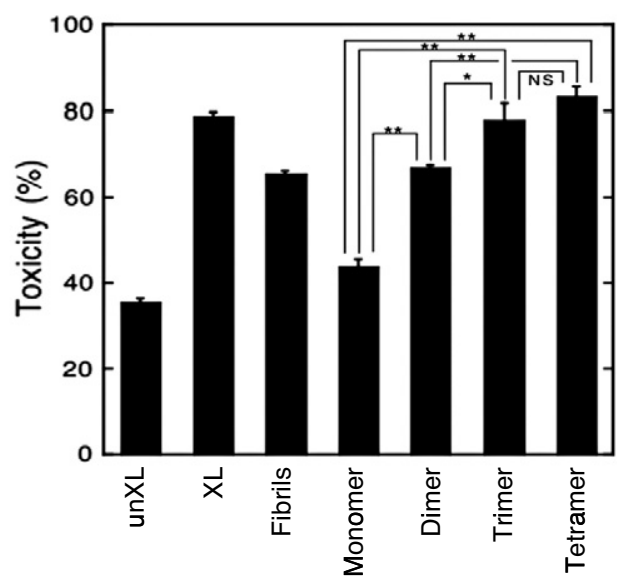

Fig. 7. Photo-inducible cross-linking strategies to elucidate the structural bases of A $\beta$ self-assembly and stabilize LMW oligomeric intermediates. (a) Structure of the photo-inducible phenylalanine analogue (tfmd-Phe) containing a tfmd group and of the active carbene species generated upon irradiation. (b) Negative-staining TEM micrographs showing that the presence of $\mathrm{tfmd}$-Phe in $\mathrm{A} \beta^{*}{ }_{16-22}$ does not influence the structure of amyloid fibrils obtained from this peptide. (b and $\mathrm{c}$ ) Reproduced from Smith et al. ${ }^{46}$ with permission. (c) Possible arrangements of tfmd-Phe pairs within antiparallel $\beta$-sheets. Top panel: Offset stacked packing at sites where no hydrogen bonds (NHB) are flanking the paired residues. Bottom panel: Edge-to-face staking model, predicted by computational methods ${ }^{47}$ to occur mostly at sites where the facing aromatic residues are flanked by hydrogen bonds (HB). (d) Schematic depiction of illustrating possible mechanism of action of Ru(II) $\mathrm{bpy}_{3}^{2}$, the photo-inducible cross-linker used in PICUP experiments. Photolysis of the ruthenium(II) tris-bipyridyl [Ru(II) $\mathrm{bpy}_{3}^{2+}$ ] organometallic complex generates excited states that donate one electron to persulfate, cleaving the $\mathrm{O}-\mathrm{O}$ bond and generating one sulfate ion and one sulfate radical, as well as the potent oxidant $\mathrm{Ru}(\mathrm{III})$. Both $\mathrm{Ru}(\mathrm{III})$ and the sulfate radical can participate in protein-protein cross-linking involving tyrosine residues and nucleophilic sidechains. ${ }^{43}$ Adapted from Fancy and Kodadek ${ }^{43}$ [Copyright (1999), National Academy of Sciences, USA] and Bitan et al. ${ }^{48}$ [Copyright (1999), National Academy of Sciences, USA]. (e) SDS-PAGE analysis of cross-linked and purified A $\beta_{1-40}$ oligomers. Lane 1: Crude $\mathrm{A} \beta_{1-40}$ preparation directly after PICUP. Lane 2: Mix of pooled excised bands after alkaline extraction. Lanes 3-6: Purity analysis of isolated cross-linked species. Lane 7: Negative control (empty gel piece subjected to the extraction protocol). (f) Quantification of lactate dehydrogenase released from differentiated PC12 cells treated with various A $\beta_{1-40}$ species $(25 \mu \mathrm{M})$. (e and f) Adapted from Ono et al. ${ }^{49}$ [Copyright (2009), National Academy of Sciences, USA].

the formation and/or stability of the protein complexes to be characterized. In such cases, photoinduced protein cross-linking can be performed when the proteins are in solutions containing soluble molecules that rapidly generate radicals. Because of their extreme reactivity, protein-protein cross-linking is then controlled by the diffusion of these species. The original approach, termed PICUP, was developed by Fancy and Kodadek. ${ }^{43}$ Its principle is described in Fig. 7d. 
The PICUP approach is well suited for studying the transient, dynamic equilibrium between small $\mathrm{A} \beta$ oligomers due to the rapidity of the photochemical transformation (much smaller than the expected lifetime of the small $A \beta$ oligomers of interest), the high reactivity, and the small size of the active crosslinking species. The first PICUP studies performed by Bitan et al. on freshly isolated LMW $\mathrm{A} \beta_{1-40}$ preparations obtained by gel-filtration chromatography identified a distribution of species ranging from monomer to pentamer, with the occasional detection of hexamers and heptamers. The authors also used the PICUP approach to demonstrate that these $A \beta_{1-40}$ oligomers are in rapid equilibrium with monomers/dimers. ${ }^{54}$ The differences in oligomeric states between $A \beta$ peptides of different lengths, from $A \beta_{1-39}$ to $A \beta_{1-43}$, were also studied using PICUP by Bitan et al. ${ }^{48}$ LMW preparations of both $A \beta_{1-40}$ and $A \beta_{1-42}$, purified by size-exclusion chromatography, were cross-linked and analyzed by gel electrophoresis. While $A \beta_{1-39}$ and $A \beta_{1-40}$ are very similar, the presence of Leu41 shifts the oligomeric state preference of the peptide toward pentamers/ hexamers, while the 42nd residue is required for the formation of heptamers and larger species.

Recently, Ono et al. characterized $A \beta_{1-40}$ using PICUP by purifying the covalently cross-linked oligomeric species. ${ }^{49}$ "Crude" (freshly dissolved, without chromatographic purification) $A \beta_{1-40}$ preparations were incubated with $\mathrm{Ru}(\mathrm{II}) \mathrm{bpy}_{3}^{2} / \mathrm{S}_{2} \mathrm{O}_{8}^{2-}$ and irradiated for $1 \mathrm{~s}$ before the separation of the oligomers by SDS-PAGE (Fig. 7e). Purification of defined oligomers, up to the tetramer, was achieved by excision of the gel and removal of the Coomassie dye and SDS, followed by dialysis. Pentamers and higher-order species were not purified due to their low abundance. The authors then characterized the secondary structure of the purified oligomers by circular dichroism spectroscopy and observed a high correlation between the oligomer order and an increase in $\beta$-sheet content, consistent with these oligomers being on the pathway to amyloid formation. Moreover, each of the purified oligomeric species could seed the fibrillization of an uncrosslinked crude $A \beta_{1-40}$ preparation, as determined by ThT binding assays, ${ }^{49}$ because co-incubation of the purified oligomers with crude peptide solution (containing mostly monomeric $A \beta_{1-40}$ ) eliminated the characteristic lag time of amyloid fibril growth that is the hallmark of nucleation-dependent polymerization. ${ }^{55-57}$ Thus, $A \beta_{1-40}$ dimers, trimers, and tetramers can nucleate the fibrillization of the peptide. As a negative control, purified cross-linked monomer was used; no seeding effect was observed, consistent with the need for monomers to nucleate before fibril elongation occurs. Because oligomeric $\mathrm{A} \beta$ species have been postulated numerous times to be the main toxic species in the pathogenesis of $\mathrm{AD}^{58-63}$ (however, in these cases, "oligomers" were not well defined due to the inability to isolate and characterize these metastable units ${ }^{64}$ ), Ono et al. examined the toxicity of their purified oligomers toward differentiated PC12 cells using lactate dehydrogenase release assays and 3-[4,5-dimethylthiazol2-yl]-2,5-diphenyltetrazolium bromide-based viability assays. Interestingly, a striking correlation was observed between increasing oligomer order and increasing toxicity (Fig. 7f), with trimers and tetramers as the most toxic species, while the dimer displayed an intermediate effect that was similar in magnitude to those of $A \beta_{1-40}$ fibrils. The study performed by Ono et al. shows a very elegant structure-function relationship between low-order $A \beta_{1-40}$ oligomers. Increased oligomerization was associated with increased $\beta$-sheet proportion, fibril nucleation capacity, and cytotoxicity. Higher-order oligomers could not be studied, however, due to the exponential decrease in the abundance of species larger than tetramers following PICUP.

As shown by the experiments with $A \beta$, PICUP permits the study of rapidly exchanging oligomers due to the fast kinetics of the photolysis process and the reactivity of the generated cross-linking elements. However, the interactions identified depend mostly on the reaction between aromatic residues and the radicals generated by the irradiation of $\mathrm{Ru}(\mathrm{II}) \mathrm{bpy}_{3}^{2}$ in the presence of persulfate; peptide backbones also react but much less than aromatic side chains due to the lack of stabilization of the protein radical by resonance. ${ }^{54}$ This is exemplified by TTR in which such residues are present in "intradimer" interfaces but not at dimer-dimer interfaces, ${ }^{65}$ thus explaining the quasi-absence of tetrameric species detected by SDS-PAGE following PICUP. ${ }^{54}$ Furthermore, artifactual oligomers are often observed using PICUP, through diffusion-controlled crosslinking of noninteracting molecules. Such artifacts must be carefully identified, for example, using the appropriate mathematical models, to distinguish between them and the actual oligomers that existed prior to cross-linking. ${ }^{54}$

The PICUP approach has also been applied for the stabilization and characterization of dynamic oligomers of other amyloidogenic proteins. ${ }^{66}$ In particular, Piening et al. showed that scrapie prion proteins could be intramolecularly cross-linked, even from crude brain extracts, without losing their ability to induce misfolding and aggregation of $\operatorname{PrP}^{\mathrm{c}}$, thus suggesting that carefully optimized photocross-linking does not significantly perturb the structure of $\mathrm{PrP}^{\mathrm{PC}}$ aggregates. ${ }^{\mathrm{g}}$ Early $\alpha$-synuclein $(\alpha$-syn) oligomers could also be stabilized by PICUP, suggesting an equilibrium between monomers, dimers, and trimers, although higher-order species could not be ruled out. ${ }^{68}$ The authors furthermore suggested that $\alpha$-syn dimers and trimers could act as seeds in the nucleation-dependent fibrillization of the protein. 


\section{From short peptides to full-length amyloid-forming proteins?}

With the exception of $A \beta$ and IAPP that are relatively short proteins, applications of switch elements and unnatural amino acids to gain control over the conformation and assembly of amyloid-forming proteins have focused on short fibril-forming model fragments of the amyloidogenic protein of interest. However, full-length sequences of amyloid-forming proteins with switchable groups are far more relevant model systems to elucidate the assembly and toxic mechanisms of these proteins in vivo. The introduction of switch elements into full-length proteins is largely hindered by the general synthetic intractability of aggregation-prone amyloid-forming proteins, which can sometimes be hundreds of residues in length. Unnatural amino acids, such as switch elements, can be introduced at any desired region of the protein by employing total chemical synthesis methods, which enable proteins on the order of $\sim 150$ residues to be built by connecting fragments by a series of native chemical ligation (NCL) reactions ${ }^{69-73}$ (discussed below). Alternatively, protein semisynthetic approaches in which a synthetic fragment is connected to a recombinantly expressed protein fragment through a NCL reaction may be employed ${ }^{71,73-76}$ (discussed below). Recent results have shown that the amyloidogenic proteins $A \beta^{77}$ the prion protein ${ }^{78}$ and the microtuble associated protein taut can be prepared by semisynthetic strategies, underscoring the potential for the introduction of switch elements into full-length amyloid-forming proteins. Moreover, Vila-Perello et al. recently incorporated a single photocleavable $O$-acyl switch element with an Nvoc protecting group at Ser35 of the fulllength split DnaE intein to gain control over protein trans-splicing activity. ${ }^{79}$ This is the first example of the application of $\mathrm{O} \rightarrow \mathrm{N}$ acyl migration to control the activity of a full-length protein.

Given that the technology exists to introduce unnatural amino acids and switch elements into full-length proteins, the application of these approaches to amyloid-forming proteins appears to be highly feasible. Light-activated switch elements are particularly desirable in this respect because they offer spatiotemporal control over protein structure and are compatible with in vivo studies. The application of the chemical tools outlined in this review to full-length proteins may lead to substantial advancements in unraveling the toxic structures and mechanisms of these elusive proteins.

\$http:/ / onlinelibrary.wiley.com/doi/10.1002/chem. 201103032/abstract

\section{The Role of PTMs in Regulating Protein Aggregation and Amyloid Formation}

Several amyloid-forming proteins are subject to a wide range of PTMs, including phosphorylation, ubiquitination, truncation, acetylation, and nitration. Certain posttranslationally modified forms of these proteins are enriched in pathological inclusions and correlate well with the pathology and disease progression in humans or animal models of the disease. For instance, hyperphosphorylation of $\mathrm{Tau}^{80}$ is widely recognized as the primary trigger for Tau aggregation and neurofibrillary tangle formation in AD. Moreover, the majority of $\alpha$-syn within Lewy bodies (LBs) is phosphorylated at Ser129. ${ }^{81}$ Although the majority of PTMs of amyloid-forming proteins were identified within the inclusions associated with their respective diseases, it remains unclear whether all disease-associated PTMs promote or inhibit protein aggregation and neurotoxicity in vivo. Multiple and/or different PTMs can occur in vivo on the same protein, and in many cases, these modifications tend to cluster within specific domains, suggesting that they may regulate each other. Therefore, elucidating the molecular mechanisms underlying PTMs and the consequences of such modifications on the biochemical, structural, aggregation, and toxic properties of these proteins is essential for unraveling the molecular basis of the function(s) of these proteins in health and disease. Ultimately, this goal can only be achieved under conditions that allow the site-specific introduction of single or multiple PTMs in the protein of interest and the preparation of these proteins in sufficient amounts to allow for detailed biochemical and biophysical studies. Unfortunately, the enzymes such as kinases, E3 ligase, and proteases that are involved in regulating the PTMs that occur in amyloid-forming proteins remain unknown. Furthermore, many of the enzymes that have been identified lack specificity or have low efficiency, thus precluding the preparation of homogeneously modified forms of amyloid-forming proteins.

\section{Chemical synthesis}

The site-specific introduction of unnatural or modified amino acids into peptides and proteins can be achieved using different chemical approaches, including SPPS, NCL, or expressed protein ligation (EPL). In SPPS, polypeptides are assembled stepwise from the C-terminus to the $\mathrm{N}$-terminus on a solid support. Although SPPS provides great flexibility for the site-specific introduction of one or more unnatural amino acids, its use remains limited to the synthesis of peptides of 50-80 residues in length, depending on the sequence. Several amyloidogenic peptides of various lengths have been routinely 
prepared using SPPS. ${ }^{5,82,83}$ However, the synthesis, purification, and handling of many of these amyloidforming peptides (e.g., $A \beta$ and IAPP) are often plagued by protein aggregation and still present many challenges. The polyQ stretch of the Huntingtin protein is especially difficult to synthesize and purify. Recently, microwave-assisted SPPS allowed the synthesis of exon 1 of the Huntingtin protein. ${ }^{84}$

To overcome the size limitation of SPPS, Kent et al. developed and pioneered approaches for constructing large proteins based on the chemoselective condensation of two or multiple unprotected peptides in aqueous buffers at physiological $\mathrm{pH}$ values. The reaction is called NCL and involves the condensation of an N-terminal peptide bearing a C-terminal thioester and a C-terminal peptide containing an N-terminal Cys to form an amide bond with a Cys at the ligation site (Fig. 8a). Figure 8a shows the chemoselective transesterification reaction that forms a native peptide bond at the ligation site. Until recently, one major drawback of the total chemical synthesis of proteins has been the introduction of $\mathrm{Cys}$ mutations at single or multiple sites to facilitate NCL; many proteins do not have Cys at the desired ligation site(s). The necessity of having a Cys at the ligation site can be circumvented by choosing ligation sites at native alanine residues within the protein because alanine residues are much more common in proteins than cysteines. In this case, Ala at the ligation site is mutated to Cys to allow for NCL and then converted back into Ala by desulfurization (Fig. 8b). ${ }^{85,86}$ In addition, several $\beta$-thiol-containing amino acid analogues have been synthesized and used to allow NCL and synthesis of proteins followed by desulfurization to generate native phenylalanine, leucine, and Thr, among others, thus eliminating the need to introduce Cys residues (Fig. 8b) ${ }^{87-91}$ In more than 900 reports, NCL has been widely applied in chemoselective ligation methods to introduce unnatural amino acids in peptides and protein. ${ }^{73,92}$ In particularly, NCL has allowed the synthesis of a wide range of proteins of increasing size, up to 304 amino acids (the tetraubiquitin protein). ${ }^{93}$ Complex proteins have also been generated using NCL. The most prominent examples include the synthesis of catalytically active enzymes such as human immunodeficiency virus-1 protease, ${ }^{94}$ human group II secretory phospholipase A2, ${ }^{95}$ and human lysozyme. ${ }^{96}$ Transmembrane proteins, such as the M2 protein from influenza A virus that acts as a proton channel, have also been generated by NCL. ${ }^{97}$

\section{Expressed protein ligation}

The reduced solubility and folding capacity of many amyloid-forming peptide fragments, as well as the difficulties associated with carrying out multiple ligation reactions, have presented some challenges that limit the utility of NCL for preparing large proteins, particularly those containing multiple folded domains. To overcome these limitations, two independent groups have developed an alternative strategy that combines the advantage of recombinant DNA technology and SPPS to prepare large proteins that are not accessible by chemical synthesis and NCL alone. ${ }^{74,98}$ This approach is termed EPL. EPL involves an NCL reaction between a longer sequence produced in E. coli and a second fragment containing the modified amino acid(s) produced by SPPS (Fig. 8a, c and d). The EPL approach also requires a fragment possessing a Cterm thioester and a fragment possessing an $\mathrm{N}$-term Cys residue. Depending on the position of the modification, proteins can be expressed either in bacteria as a thioester or with an N-terminal Cys (Fig. $8 \mathrm{c}$ and d). Classic methods to generate recombinant proteins in E. coli rely on endogenous methionine aminopeptidases that cleave the first methionine or on proteases that cleave a specific sequence such as a tobacco etch virus (TEV) or factor Xa protease recognition sequence just upstream of a Cys residue to generate a protein with an $\mathrm{N}$-terminal Cys residue (Fig. 8d) ${ }^{99-101}$ Recombinant protein thioesters can be obtained by using engineered proteins called inteins. Inteins are self-processing domains that mediate naturally occurring protein splicing. In this process, an internal polypeptide- the intein-is self-excised from a precursor protein and in the process ligates the flanking exteins ( $\mathrm{N}$ - and C-exteins) ${ }^{102-104}$ For the production of protein thioesters, the intein is genetically engineered to undergo cleavage at only the N-term extremity (Fig. 8c). ${ }^{105,106}$ In addition, several chemical methods for generating peptide thioesters using SPPS have been described. ${ }^{3,107}$

Advances in EPL methodologies have facilitated the synthesis and characterization of large proteins and have enabled the introduction and characterization of a large set of site-specific PTMs. However, the introduction of site-specific modifications by the EPL method is restricted to residues located 50-70 amino acids from the $\mathrm{N}$-terminus or the $\mathrm{C}$-terminus of the protein (i.e., the fragments that can be prepared by SPPS). Moreover, the target protein and the intein must also be correctly folded after expression in E. coli in order for the intein-mediated splicing to occur. ${ }^{108}$

\section{Nonsense suppression methodology}

An alternative approach for the site-specific incorporation of modified amino acids was pioneered by Schultz et al. and is based on the generation of suppressor tRNA/tRNA synthetase pairs that have been evolved to allow the site-specific incorporation of unnatural amino acids. More than 50 unnatural amino acids have been successfully incorporated in prokaryotes and eukaryotes using this approach. ${ }^{109,110}$ This methodology has been applied for the incorporation of photoactivatable 
(a)

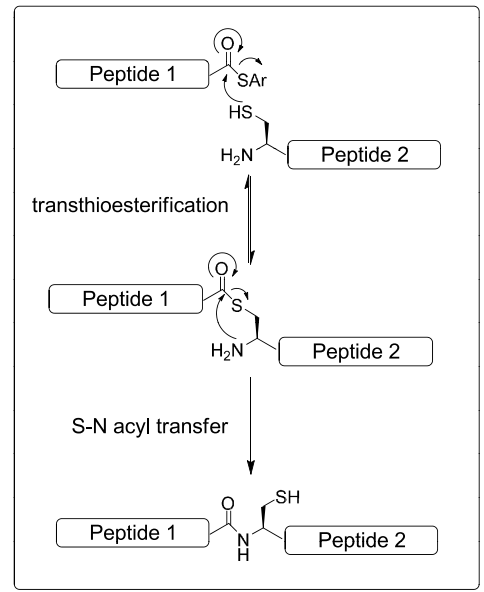

(b)

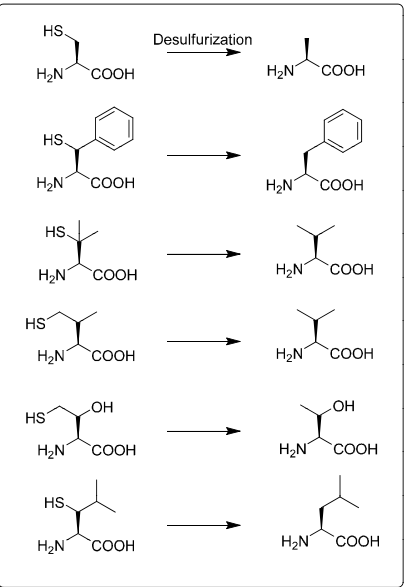

(c)

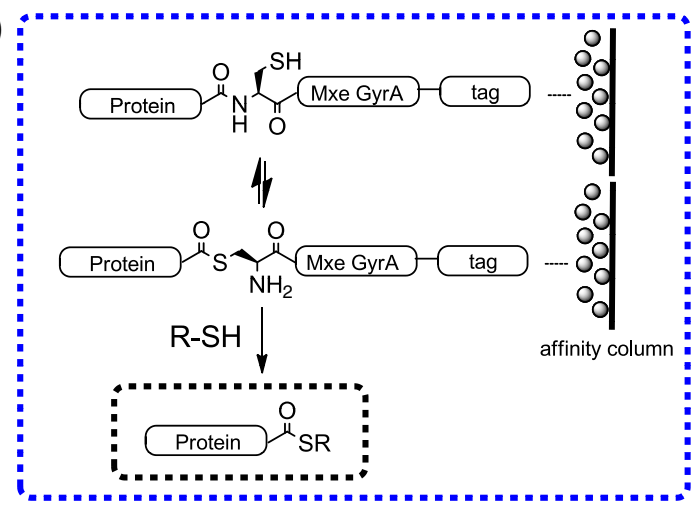

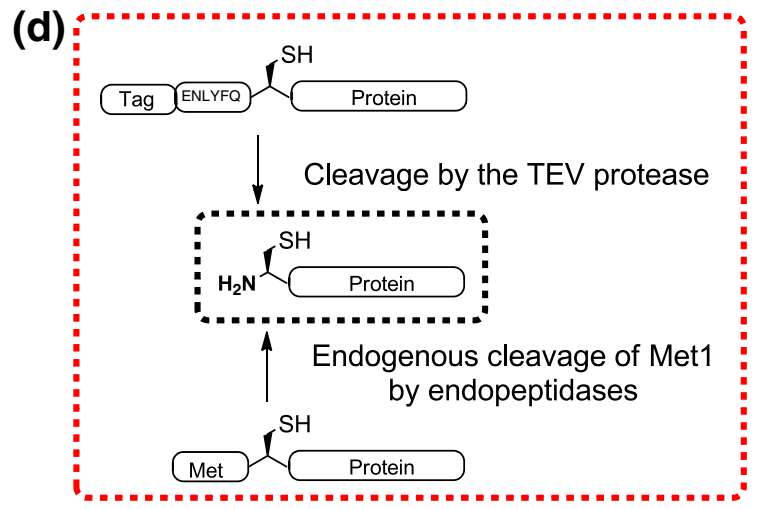

Fig. 8. Principles of NCL and EPL. (a) NCL: The first step in NCL, after the activation of peptide 1's thioester to aryl form, is the reversible thiol-thioester exchange between the electrophilic thioester carbonyl center of peptide 1 and the nucleophilic thiol of the $\mathrm{N}$-terminal Cys of peptide 2 . This transthioesterification reaction is then leading to a spontaneous, chemoselective S-N acyl migration via a five-membered transition state to form a native peptide bond with a Cys residue, the ligation site. The presence of additional Cys residues in one or both fragments does not affect the regioselectivity of the ligation because the irreversible intramolecular S-N shift can only occur at the N-terminal Cys residue. Either fragment (peptide 1 or peptide 2) can be a protein produced by recombinant techniques [described in (c) and (d)] for protein semisynthesis by EPL. (b) Strategies to allow NCL in cysteine-lacking proteins. In most cases, NCL can be performed at an alanine residue: alanine is temporarily replaced by cysteine, and a final desulfurization step using Raney-nickel-based or metal-free-based methods restores the alanine residue at the ligation site. ${ }^{85,86}$ Unnatural amino acids containing a $\beta$ - or $\gamma$ mercapto group are also shown; they allow NCL at phenylalanine, ${ }^{87}$ valine, ${ }^{88,89}$ threonine, ${ }^{90}$ and leucine. ${ }^{91}$ (c) Generation of recombinant protein thioesters for use in EPL. The desired recombinant protein thioester can be prepared using the intein strategy. The first step in the splicing process involves an N-S acyl shift that brings the protein fragment of interest to the thiol group of the first residue of the intein. A thioester bond will be formed between the protein of interest and the intein, which is susceptible to cleavage by exogenous thiols such as DTT or sodium 2-mercaptoethanesulfonate. A purification tag (chitin binding domain) at the C-terminus of the mutated intein allows for a quick recovery of the purified protein thioester. (d) Recombinant production of proteins containing an N-terminal cysteine. This can be achieved either using a protease cleavage site (such as the TEV protease target sequence) that may be preceded by a purification tag or by taking advantage of $E$. coli's methionine aminopeptidase that will cleave the first methionine residue of the protein of interest, leaving it with an N-terminal cysteine.

amino acids or tyrosine analogues for the study of ion channels and nicotinic acetylcholine receptors in Xenopus oocytes, mammalian cells, and primary neurons. ${ }^{111-115}$ Interestingly, this technique has not been extended for the characterization of amyloid proteins. One major limitation of the nonsense suppression method is the requirement for large quantities of aminoacylated tRNAs and the small number of unnatural amino acids that can simultaneously incorporated in a protein. ${ }^{116}$

Here, we present recent results from our group and others that illustrate the potential of using chemical and semisynthetic strategies for preparing proteins to study the effect of specific PTM on the 
folding, aggregation, and biochemical properties of three different amyloid-forming proteins: $\alpha$-syn, the prion protein, and the $A \beta$ peptide.

\section{a-Synuclein}

$\alpha$-Syn is a 140 -amino-acid unfolded protein and is the primary constituent of the fibrillar inclusions, LBs, ${ }^{92,117}$ that are found in the brains of PD patients and patients suffering from other neurodegenerative diseases such as multiple system atrophy and dementia with LBs, hereinafter collectively referred to as "synucleinopathies". ${ }^{118}$ Increased expression of $\alpha$-syn (gene duplication or triplication) or the $\alpha$ syn mutations A30P, E46K, and A53T enhance its fibrillization rate leading to early-onset forms of PD. ${ }^{119-122}$ The identification of several PTMs in $\alpha-$ syn within LBs suggested that these modifications actively participate in promoting $\alpha$-syn aggregation and LB formation. ${ }^{123}$ However, a detailed understanding of the role of each PTM in $\alpha$-syn aggregation and toxicity remains elusive because the natural enzymes involved in regulating these PTMs remain unknown. Understanding the role of specific PTMs in $\alpha$-syn aggregation and toxicity is essential for elucidating the molecular basis of neurodegeneration and the pathogenesis of PD and other synucleinopathies. Moreover, such an understanding may facilitate the identification of novel therapeutic targets and strategies for PD and related disorders. ${ }^{24}$

Although several enzymes have been shown to mediate $\alpha$-syn phosphorylation, ubiquitination, and truncation in vitro, many of these enzymes are either nonspecific or inefficient; the natural enzymes involved in the phosphorylation of $\alpha$-syn at S87, S129, and Y125 are unknown, but several in vitro and in vivo experiments have identified that several candidate kinases (CKI and CKII) and G-proteincoupled receptor kinases phosphorylate $\alpha$-syn at S129 and S87 125,126 and that Polo-like kinases phosphorylate at S129. ${ }^{127,128}$ Fyn, Lyn, and c-Frg phosphorylate at Y125, ${ }^{129,130}$ and Syk phosphorylate all three C-terminal tyrosines. ${ }^{130-132}$ With respect to the ubiquitination of $\alpha$-syn that occurs in LBs at K12, K21, and K23, several E3 ligases have been proposed to monoubiquitinate and polyubiquitinate $\alpha$-syn in vitro and in vivo: $\mathrm{SIAH}, 133,134$ CHIP, ${ }^{135}$ RAF6, $^{136}{ }^{\text {E6AP }}{ }^{137}$ and Nedd4. ${ }^{138}$ Details concerning previous reports about those PTMs have been reviewed elsewhere. ${ }^{124}$ Other approaches based on the use of mimicking mutations (e.g., phosphomimics) have yielded controversial results, in part, because these mimics do not reproduce all aspects of these modifications. ${ }^{131}$ Moreover, it is important to stress that there are no natural amino acids that can mimic phosphotyrosine. In addition, the introduction of mimicking mutations is irreversible and does not allow the investigation of PTMs under physiological conditions at which these modifications are reversible (e.g., phosphorylation).

\section{Strategies for the study of PTMs at the $\mathrm{N}$-terminus of $\alpha$-syn}

To study N-terminal PTMs, including N-terminal acetylation and monoubiquitination, we developed an EPL strategy (Fig. 9a and b). ${ }^{139}$ Specifically, an $\mathrm{N}$-terminal peptide fragment of $\alpha$-syn containing $\mathrm{N}$-acetylated methionine or the unnatural amino acid $\delta$-mercaptolysine ${ }^{140}$ at the desired residue was synthesized. The use of $\delta$-mercaptolysine developed by Kumar et al. enabled us for the first time the facile site-specific conjugation of ubiquitin into the desired lysine residues of $\alpha$-syn and other proteins. ${ }^{93,141}$ $\mathrm{N}$-terminal ubiquitinated $\alpha$-syn was prepared by the ligation of two fragments under NCL conditions: a recombinantly expressed $\alpha$-syn fragment comprising residues 19-140 and bearing an N-terminal Cys $\alpha$-syn(19-140) and a synthetic peptide thioester comprising the $\mathrm{N}$-terminal residues $1-18$ and bearing a protected $\delta$-mercaptolysine (Fig. $9 \mathrm{~b}$, bottom panel) at the desired lysine residue, $\alpha$-syn(1-18)-SR. Ubiquitination was then achieved by addition of the T7-Ub-SR to the full-length $\alpha$-syn(1-140) presenting the free $\delta$-mercaptolysine to generate the first monoubiquitinated $\alpha$-syn variant at $\mathrm{K} 6$, with a native isopeptide bond. ${ }^{139}$ Biophysical studies of T7-Ubi- $\alpha$-syn(K6) demonstrated that the conjugation of one ubiquitin moiety at K6 stabilized the monomeric $\alpha$-syn and prevented its fibrillization in vitro (Fig. 9d). Moreover, no significant accumulation of oligomers or higher-molecular-weight aggregates was observed upon incubation of T7-Ubi- $\alpha-\operatorname{syn}(\mathrm{K} 6)$ for 10 days. These studies provided strong evidence that ubiquitination inhibits $\alpha$-syn aggregation. Furthermore, these studies suggest that ubiquitination of $\alpha$-syn within LBs may occur after fibrillization and may be an active cellular response aimed at clearing $\alpha$-syn aggregates. Current efforts in our laboratories are focused on determining the effects of ubiquitination at other lysine residues and exploring potential cross-talk between ubiquitination and other PTMs in $\alpha$-syn. Using a similar strategy, we were recently able to study the effects of $\mathrm{N}$-terminal acetylation of $\alpha$-syn, which had remained unexplored prior to our investigation despite the fact that most of native $\alpha$ syn is N-terminally acetylated. ${ }^{123}$ These studies would not have been possible without semisynthetic $\alpha$-syn. This approach could also be extended to study the effect of phosphorylation, ubiquitination, or sumoylation on exon 1 of the Huntingtin protein or cross-talk between these modifications, all of which occur within the first $16 \mathrm{~N}$-terminal residues of exon $1 .^{142-144}$ Furthermore, recent advances by Kumar et al., Kumar et al., and Bavikar et al., using $\mathrm{NCL}$, provided access to oligo-ubiquitin chains of different lengths and different inter-ubiquitin 
(a) C-Terminal Modifications: Semisynthesis

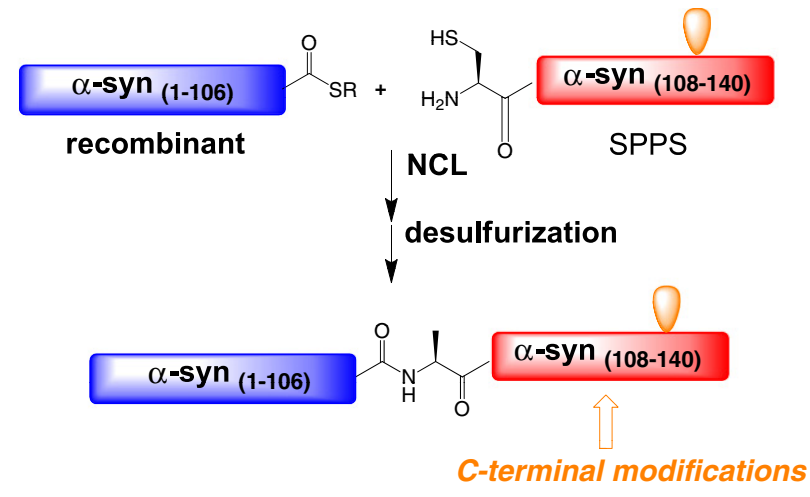

(b) N-Terminal Modifications: Semisynthesis

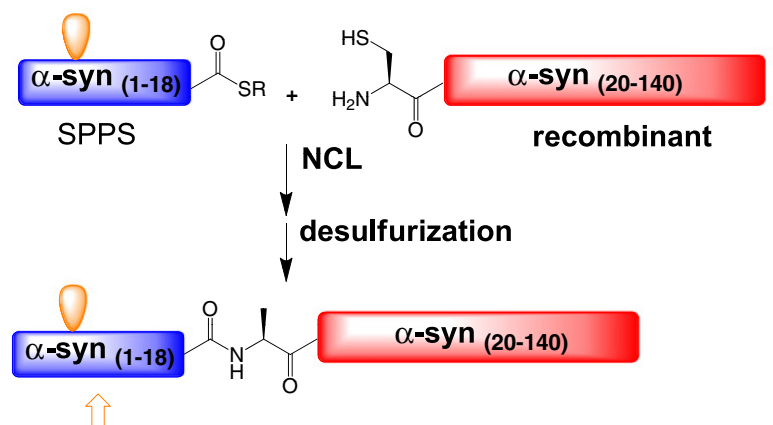

N-terminal modifications
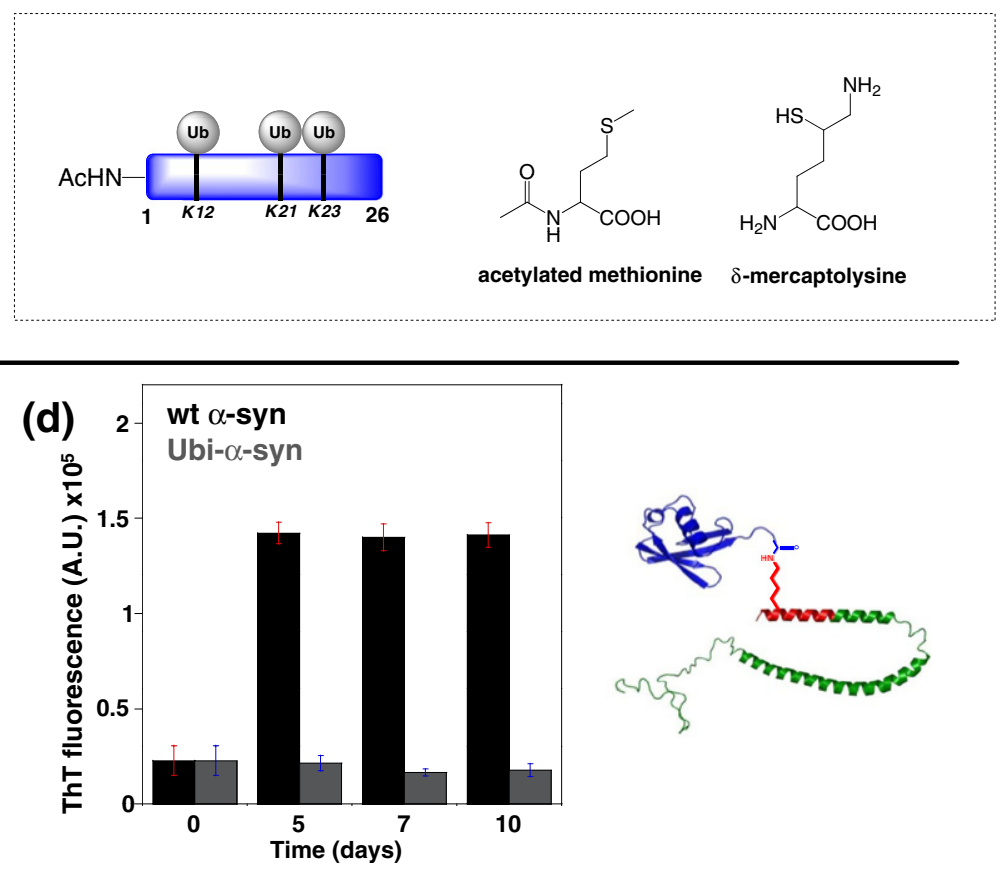
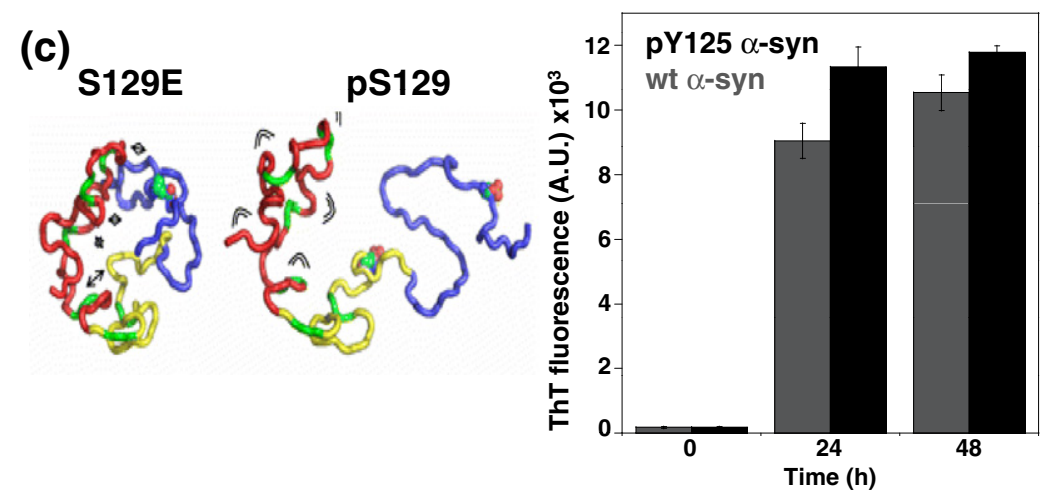

Fig. 9 (legend on next page) 
linkages. ${ }^{93,141,145}$ Through protein semisynthesis, segmental isotopic labeling of one monomer in K48- and K33-linked di-ubiquitin chains was demonstrated, allowing the study of monomer-specific structural and conformational features by nuclear magnetic resonance (NMR). ${ }^{146}$ Extending these advances to amyloid proteins will permit the investigation of the effect of the ubiquitin chain length and types of interchain linkages on the function, aggregation, and clearance of these proteins.

\section{Strategies for the study of PTMs at the C-terminus of $\alpha$-syn}

The majority of the disease-associated PTMs (truncation, phosphorylation, and nitration) occur within the C-terminal region comprising residues $120-136 .{ }^{124}$ To probe the role of C-terminal PTMs in $\alpha$-syn, we developed and optimized a general and efficient semisynthetic strategy that enables the sitespecific introduction of single or multiple PTMs in $\alpha$-syn to generate milligram quantities of homogeneously C-terminal modified forms of $\alpha$-syn. Our goal was achieved using an EPL strategy involving an NCL reaction between a synthetic peptide corresponding to $\alpha-\operatorname{syn}(\mathrm{A} 107 \mathrm{C}-140)$ and the recombinant $\alpha$-syn fragment $\alpha$-syn(1-106) thioester (Fig. 9a). ${ }^{147}$ We exploited the approach for the generation of pure phosphorylated $\alpha$-syn at Y125 and were able for the first time to investigate the role of selective phosphorylation of Y125 in the structure, fibrillization propensity (Fig. 9c), membrane binding, and subcellular localization of semisynthetic pY125 $\alpha$ syn. We reported that phosphorylation at Y125 did not have a major impact on the structure of $\alpha$-syn and its fibrillization propensity, in contrast to phosphorylation at S129 that resulted in a broader conformation and inhibited the aggregation of the protein (Fig. 9c). Most importantly, the use of semisynthetic pY125 $\alpha$-syn enabled us to better design and interpret experiments performed in mammalian cells and provided a rationale for why this modification is not prominently detected in vivo. We observed that pY125 undergoes rapid dephosphorylation upon addition to cell lysates or microinjection into neurons. Dephosphorylation of pY125 was blocked by the addition of phosphatase in- hibitors. These results confirmed previous data suggesting that phosphorylation at Y125 is very tightly regulated so that the levels of pY125 are maintained at very low levels but increases significantly in cell culture, primary neurons, and brain tissues, upon treatment with the phosphatase inhibitor pervanadate. ${ }^{148-150}$ Our studies demonstrate the value of homogeneously modified forms of $\alpha$-syn and stress the importance of considering the stability and dynamics of modified variants of $\alpha$ syn in future studies aimed at evaluating and correlating specific PTMs with disease progression. The protocols used for the analysis and preparations of samples must be modified accordingly.

The clustering of PTMs, which play critical roles in modulating its subcellular localization, membrane binding, and interaction with other proteins, in the $\mathrm{N}$ - and C-terminal regions of $\alpha$-syn, suggests that these modifications may be involved in the regulation of $\alpha$-syn function in health and disease. This hypothesis is further supported by the fact that the majority of these PTM sites are highly conserved across different species. In addition, the close proximity of these different modifications suggests that they may act in concert, and cross-talk between different PTMs may constitute an additional molecular switch for regulating the dynamics of $\alpha$-syn function and aggregation. The approaches presented above have allowed the preparation of all disease-associated $\alpha$-syn PTMs and will provide unique opportunities to study these processes, facilitate the development of novel assays for target identification, and explore if any of these PTMs correlate with disease progression and severity.

\section{Prion Proteins}

Prions are $\sim 230$-residue cell-surface glycoproteins ${ }^{151}$ produced by the Prnp gene that acts as infectious agents involved in the pathogenesis of transmissible encephalopathies. Like other amyloidogenic proteins, misfolding toward a toxigenic $\beta$-sheet-rich conformation and subsequent aggregation are the first steps toward pathogenesis. Native prion protein displays mainly an $\alpha$-helical structure, ${ }^{152}$ with a disulfide bond between helices 2 and $3 .{ }^{153}$ However,

\footnotetext{
Fig. 9. Semisynthetic strategies for the introduction of modifications at the N-terminus and the C-terminus of $\alpha$-syn. (a) Semisynthetic strategies for the introduction of modifications at the C-terminus: phosphorylated Ser, phosphorylated tyrosine, and nitrated tyrosine have been introduced in the C-terminus of $\alpha$-syn using semisynthesis. (b) Semisynthetic strategies for the introduction of modifications at the $\mathrm{N}$-terminus: ubiquitin and $\mathrm{N}^{\alpha}$-acetylated methionine have been introduced in the N-terminal part of $\alpha$-syn. (c) Left: Phosphomimic S129E variant does not display the same conformation as phosphorylated $\alpha$-syn at S129. The structures displayed were derived from NMR data published by our group. ${ }^{131}$ Right: Phosphorylation at Tyr125 does not significantly affect the fibrillization of $\alpha$-syn as seen by ThT fluorescence. (d) Monoubiquitination of $\alpha$-syn at K6 completely prevented its fibrillization as shown by the ThT fluorescence binding assay. The schematic structure of monoubiquitinated $\alpha$-syn has been done with PyMOL, based on Protein Data Bank structures 1XQ8 and 1UBQ.
} 
pathogenic prion conformations have the distinct ability to catalyze the conversion of the physiological form ("cellular", $\operatorname{PrP}^{\mathrm{c}}$ ) to the misfolded form ("scrapie", $\operatorname{PrP}^{\mathrm{sc}}$ ), which can be explained by a "templating" behavior. ${ }^{154,155}$ In this regard, prions also serve as models for the study of other neurodegenerative disorders caused by amyloidogenic proteins, such as AD.

Prions usually exist as unmodified, monoglycosylated, and diglycosylated forms and membraneassociated forms through the addition of a C-terminal glycosylphosphatidylinositol (GPI) anchor. Several studies have suggested that the conversion of PrP to $\operatorname{PrP}^{\mathrm{sc}}$ occurs at the plasma membrane, ${ }^{156}$ to which PrP is attached via a GPI anchor. ${ }^{151}$ Membrane attachment of PrP has been shown to play a key role in the cytotoxicity of $\mathrm{PrP}^{\mathrm{sc}}$ because mice expressing only a PrP protein lacking its GPI anchor (and thus secreted as a soluble protein) do not develop spongiform encephalopathy upon prion inoculation, yet their brain tissues show evidence of amyloid deposits. ${ }^{157}$ Because several PTMs can exist on the same prion molecule, and not all PrP molecules are membrane bound, it is important to study membrane-bound PrP in isolation. However, traditional methods are not efficient for the expression and purification of posttranslationally modified $\operatorname{PrP}$ forms, thus limiting in vitro studies to either PrP modified with simple GPI mimics, such as disulfidelinked phospholipids, ${ }^{158}$ sulfolipids, ${ }^{159}$ and thioetherlinked myristoyl groups. ${ }^{160}$ Native GPI anchors, in contrast, consist of a core pseudopentasaccharide glycan (shared among mammalian GPIs) linked to target proteins at the C-terminus via a phosphoethanolamine linker. The core glycan can be further modified with a branched saccharide (up to three units) or phosphoethanolamine groups. The structure and compositions of mammalian GPI anchors have been reviewed elsewhere. ${ }^{161}$ For prion proteins, six different glycan compositions were identi- fied, but they were not fully chemically defined. For example, the lipid composition is unknown. ${ }^{162}$

\section{Semisynthesis of palmitoylated murine PrP}

Protein semisynthesis is well suited for the study of protein interactions with biological membranes, as it allows the introduction of lipophilic groups in a sitespecific manner ${ }^{163,164}$ with the possibility to introduce labels, cleavable groups such as fluorophores, ${ }^{99}$ or temporary solubilizing groups to improve the handling of hydrophobic segments. ${ }^{165,166}$ Moreover, the approach allows the use of synthetic fragments that can mimic natural membrane anchors as closely as desired. ${ }^{167}$ This strategy was chosen by Olschewski et al., who designed an EPL strategy for the semisynthesis of C-terminally di-palmitoylated murine PrP(90-232) (referred to as $\mathrm{PrP}^{\mathrm{Palm}}$ by the authors) to study the role of GPI-mediated membrane association in cellular uptake and $\mathrm{PrP}^{\mathrm{C}}$-to$\mathrm{PrP}^{\mathrm{sc}}$ conversion. ${ }^{102}$ To eliminate the need to isolate a recombinant $\operatorname{PrP}(90-232)$ thioester, Olschewski et al. employed a strategy based on protein transsplicing (described in Fig. 10a; see also Giriat and Muir $^{168}$ ). Following trans-splicing, $\operatorname{PrP}^{\text {Palm }}$ was purified and folded in the presence of dioleoyl-snglycero-3-phosphocholine (DOPC) liposomes, which produced the $\alpha$-helix-rich cellular form.

The semisynthetic $\mathrm{PrP}^{\text {Palm }}$ bound tightly to DOPC vesicles. ${ }^{102}$ Treatment of the $\operatorname{PrP}^{\text {Palm }}$-bound vesicles with TEV protease, which cleaved the protein from its lipid anchor, resulted in complete dissociation of $\operatorname{PrP}(90-232)$ from the small unilamellar vesicles (SUVs), thereby ruling out nonspecific hydrophobic interactions. Moreover, PrP $\mathrm{P}^{\mathrm{Palm}}$ was shown to form proteinase-K-resistant aggregates that resemble those formed by $\operatorname{PrP}^{\mathrm{sc}}$. Cellular internalization assays then showed that, while up to $\sim 50 \%$ of $\mathrm{PrP}^{\text {Palm }}$ could be recovered in a detergent-soluble conformation, cells treated with recombinant PrP

Fig. 10. Semisynthesis of murine prion protein. (a) Semisynthesis of lipidated murine PrP(90-232) using the split intein concept. The recombinant $\operatorname{PrP}(\mathrm{rPrP})$ was produced as a fusion protein with the N-terminal domain of the DnaE intein $\left(\mathrm{DnaE}^{\mathrm{N}}\right)$. The synthetic C-terminal fragment containing the membrane anchors was produced in two steps. First, the C-terminal domain of the DnaE intein (DnaE ${ }^{C} ; \sim 40$ residues) was produced with a C-terminal thioester by Boc-based SPPS. Then, a peptidic membrane anchor was synthesized (16-17 amino acids; bearing two palmitoyl groups on Lys residues and a PEG-based solubilizing group at the C-terminus). TEV protease cleavage sites were included to allow the removal of the solubilizing groups, the membrane anchor, or both. A first NCL was applied to obtain the various DnaE $E^{C}$ membrane anchor polypeptides. The final ligation to obtain $\operatorname{PrP}^{\text {Palm }}$ was carried after folding of the recombinant fragment $\left(\mathrm{rPrP}_{\mathrm{D}} \mathrm{DnaE}{ }^{\mathrm{N}}\right)$ and addition of $\mathrm{DnaE}^{\mathcal{E}}$ membrane anchors. Adapted from Olschewski et al. ${ }^{102}$ (b) The extent of aggregation by recombinant (unmodified) PrP in the absence (black lines) and in the presence (red lines) of DOPC SUVs as assessed by ThT binding. (c) The same experiment as in (b) was carried out using semisynthetic PrP Palm . (d) Immunocytochemical staining analysis of N2a cells transfected with $\operatorname{PrP}^{\mathrm{c}}$. (e) Same analysis as in (d), but performed on PrP Palm-treated N2a cells. (b-e) Reproduced from Olschewski et al., ${ }^{102}$ with permission. (f) Schematic depiction of the PrP-GPI semisynthetic strategy involving a recombinant $\operatorname{PrP}(90-232)$ thioester produced by intein thiolysis (top) and a synthetic GPI anchor with a Cys residue having its amino group free. (g) Chemical structure of the semisynthetic protein with a focus on the synthetic GPI anchor module. The Cys handle for NCL is labeled in green; the oligosaccharide, in blue; and the lipid moiety, in purple. ( $\mathrm{f}$ and g) Adapted from Becker et al. ${ }^{78}$ 
(a)
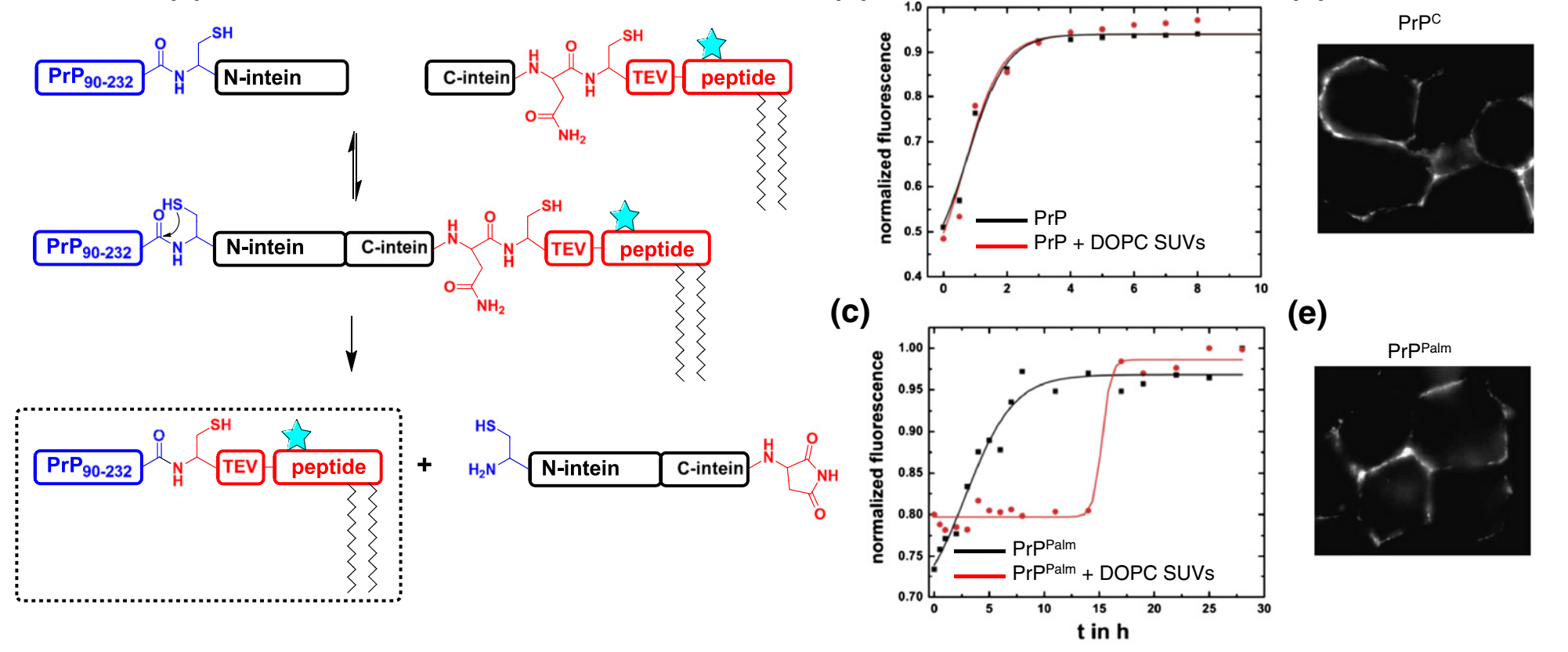

(b)

(c)

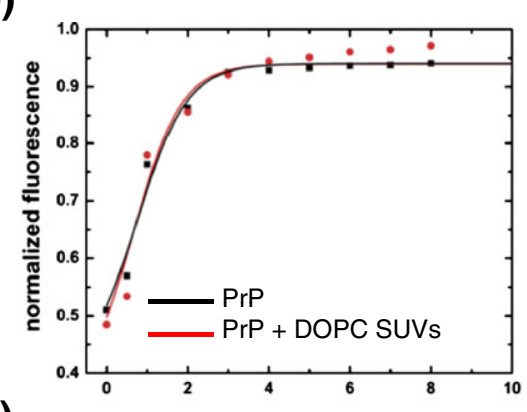

(d)

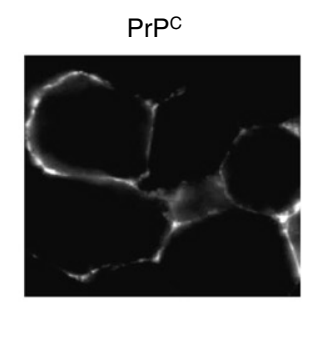

(e) (f)

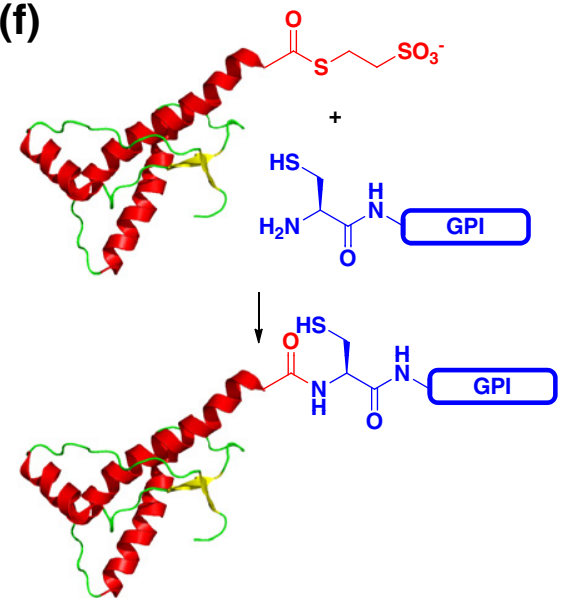

(g)

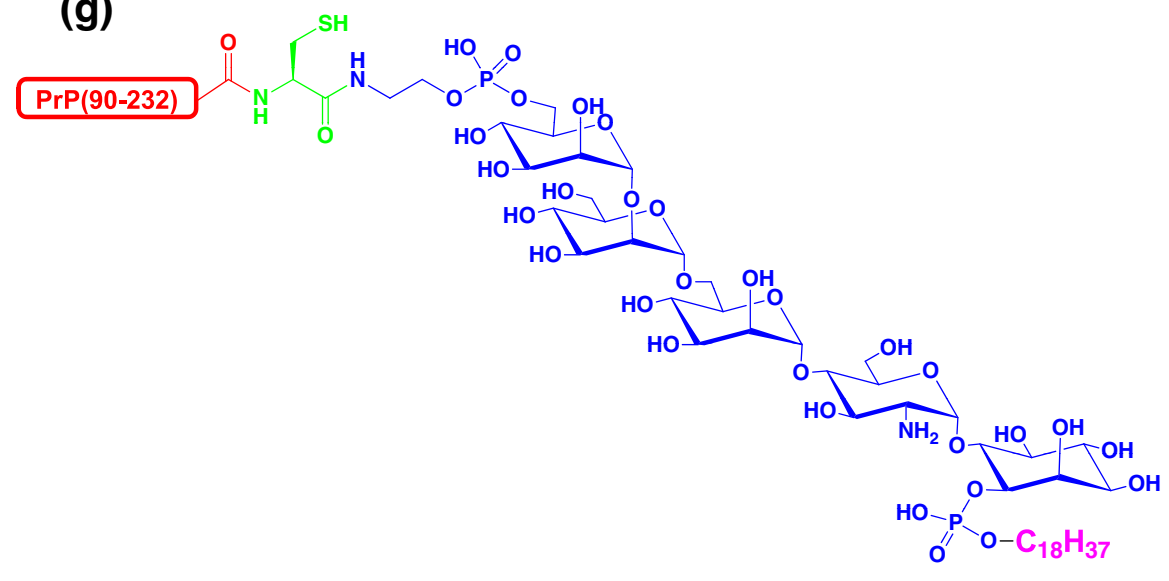

Fig. 10 (legend on previous page) 
(rPrP) only presented a detergent-insoluble form, thus suggesting that membrane association helps maintain PrP in its cellular conformation, consistent with the reduced aggregation propensity of PrP $\mathrm{Palm}^{\text {Palm }}$ (Fig. 10b and c). Furthermore, immunocytochemistry of fixed $\mathrm{PrP}^{\text {Palm }}$-treated N2a cells showed an exclusively membranous localization, similar to that of recombinantly expressed $\mathrm{rPrP}\left(\mathrm{PrP}^{\mathrm{c}}\right.$; Fig. $10 \mathrm{~d}$ and e). However, PrP Palm was not found to associate with detergent-insoluble membrane domains, contrary to what is observed in the case of rPrP. ${ }^{169}$ This suggests that the chemical nature of the membrane anchor plays an important role in determining the precise localization of membranebound $\operatorname{PrP}^{\mathrm{C}}$ and highlights the importance of using semisynthetic proteins as close to the native form as possible.

\section{Semisynthesis of GPI-anchored PrP}

The strategy described above provides a valuable tool for dissecting the consequences of PrP membrane association in a reversible manner because of the presence of a cleavable group upstream of the lipidated sequence but does not take into account the specific properties of a natural GPI anchor. Therefore, Becker et al. used a chemical approach to prepare semisynthetic PrP modified with a synthetic C-terminal GPI anchor (Fig. 10f). The GPI anchor consists of a Cys residue (for use in NCL) attached to a pseudopentasaccharide through a native ethanolamine phosphate linker observed in natural GPI anchors. ${ }^{161}$ The lipid chain (an octadecyl group) was attached via a phosphodiester bond to the 1-position of the distal inositol residue (see Fig. 10g). This more physiologically relevant GPI mimic was ligated via NCL to the C-terminus of a recombinantly expressed PrP thioester (using the intein thiolysis method described in Fig. 8c).

Folding of the resulting PrP-GPI was achieved by rapid dilution into a non-chaotropic buffered solution, which was confirmed by circular dichroism. Unlike the previous strategy reported by the same group, ${ }^{102}$ no lipid vesicles were necessary to obtain the native $\alpha$-helix-rich structure. PrP-GPI, but not non-lipidated recombinant $\mathrm{rPrP}$, bound quantitatively to DOPC SUVs, as shown by vesicle pulldown assays. $^{78}$

The synthetic GPI anchor developed by Becker et al. has the advantage of being able to induce efficient PrP membrane association, while maintaining good solubility in aqueous buffer devoid of lipid vesicles or detergents. ${ }^{78}$ In contrast, this is peptidebased GPI mimics, which require two aliphatic chains to obtain the same effect, unless an artificial solubilizing group (such as PEG) is present. ${ }^{102}$ However, the preparation of the synthetic GPI is much more challenging, requiring many more steps than the peptide-based GPI mimic. The same research group recently published a method for isolating a natural GPI anchor module consisting of a GPIattached peptide bearing an N-terminal Cys. ${ }^{170}$ This can be employed to modify any protein of interest with a GPI anchor but does not yield a homogenous preparation because it is derived from the recombinant expression of a fusion protein in yeast cells.

It should be noted that studies on the membrane association of semisynthetic PrP thus far have been carried out using artificial liposomes, which do not reflect the physiological lipid composition of neuronal membranes. The synthetic and semisynthetic strategies for preparing modified forms of PrP provide unique opportunities to elucidate the effect of different PTMs on amyloid formation in PrP and should provide important insight into the role of membranes in prion replication and toxicity.

\section{Semisynthesis of $\beta$-amyloid peptides}

Extracellular deposits of fibrillar $A \beta$ peptides, mainly the 40- and 42-residue-long forms, are hallmarks of $\mathrm{AD}$ progression. ${ }^{171}$ Understanding the roles of the various self-associated forms of $A \beta$ (i.e., soluble oligomers and fibrils) in the pathogenesis of AD and the molecular mechanisms controlling the assembly states of $A \beta$ are prerequisites for identifying efficient therapeutic strategies to target the real causes of the disorder. In particular, obtaining structures of aggregated A $\beta$ species, such as soluble oligomers, with atomic-level detail is of great interest for this purpose. Solution- and solid-state NMR are invaluable tools to achieve this, but these require the use of isotopically labeled peptides. ${ }^{172}$ While total chemical synthesis of natural (unlabeled) $A \beta$ peptides is very common (although plagued by low yields due to synthetic difficulties in part associated with on-resin aggregation $^{5}$ ), high costs of isotopically labeled amino acid building blocks for SPPS prevent the use of this method to prepare $A \beta$ peptides in sufficient quantities for NMR-based structural characterization. The classical method for producing isotopically labeled recombinant proteins, which uses cultures of appropriately transformed bacterial cells in labeled minimal media (i.e., containing $\left[{ }^{15} \mathrm{~N}\right]$ ammonium chloride as the only nitrogen source and/or $\left[{ }^{13} \mathrm{C}\right]$ glucose as the only usable carbon source), is not applicable for $A \beta$ peptides because bacterial expression results in the localization of $A \beta$ to insoluble inclusion bodies in which the Met35 residue has a high propensity to oxidize. ${ }^{173,174}$ Moreover, recombinant $\mathrm{A} \beta$ peptides are toxic to bacterial cells, thus further limiting production yields. ${ }^{98}$ To overcome this limitation, some groups have investigated the expression of the $A \beta$ peptide or its fragments as fusion proteins for NMR studies. ${ }^{175-177}$ While the yields increased dramatically, these strategies require the placement of 
protease cleavage sites between the $A \beta$ domain and the fusion partner, which leaves additional residues after its removal, thus introducing potential artifacts in the structure and aggregation properties of those peptides.

To overcome these limitations, Bockhorn et al. applied a semisynthetic strategy ${ }^{77}$ (similar in design to the one described above for $\alpha$-syn) in which the 1-29 fragment of $A \beta$ was recombinantly expressed as an intein-chitin binding domain fusion protein, which remained fully soluble but retained the initiating methionine residue and was thus referred to as Met- $A \beta_{1-29}$. Expression was efficient in both normal and minimal media, ensuring the applicability of this method for preparing isotopically labeled $A \beta$. The fusion protein was then subjected to thiolysis with sodium 2-mercaptoethanesulfonate to produce the Met-A $\beta_{1-29}-\mathrm{SR}$ thioester. The semisynthetic strategy had been designed to omit Met35 in the recombinant fragment, not only to avoid oxidative modifications but also primarily because following thiolysis of the fusion protein, the $\mathrm{N}$-terminal methionine, which is not in the native $\mathrm{A} \beta$ sequence, could be selectively removed by $\mathrm{CNBr}$-mediated cleavage. The resulting $\mathrm{A} \beta_{1-29}-\mathrm{SR}$ was then ligated with synthetic $A 30 C-A \beta_{30-40}$ (prepared by Fmoc-SPPS). Following Raney-nickelbased desulfurization the native, full-length $A \beta_{1-40}$ was obtained with yields up to $8.5 \mathrm{mg}$ per liter of expression medium. The mutant D23N, which is associated with familial forms of $\mathrm{AD}^{178}$ was also produced successfully with this method.

The approach developed by Bockhorn et al. offers the obvious advantages of higher yields and, in particular, provides access to labeled peptides at a far lower cost than that required for a fully synthetic $\mathrm{A} \beta$ peptide. ${ }^{77}$ It also offers the possibility of preparing A $\beta$ peptides with PTMs in the C-terminal domain. For example, while oxidation of Met35 to sulfoxide, which decreases $\mathrm{A} \beta$ toxicity and selfassembly, has been well investigated, ${ }^{179}$ the rarely studied sulfone form was recently found to have profoundly opposite effects. ${ }^{180}$ The preparation of $\operatorname{Met}\left(\mathrm{O}_{2}\right)-\mathrm{A} \beta$ relied on Fmoc-based total synthesis, and its yield could be improved yields by a semisynthetic approach.

The most obvious drawback of this semisynthetic approach is that only the $\mathrm{N}$-terminal recombinant fragment $A \beta_{1-29}$ can be labeled, thus restricting NMR signals to these residues (this can, however, be an advantage by simplifying the NMR spectra, as noted by the authors). Another limitation inherent to this semisynthetic strategy is that it prevents access to site-specific PTMs of $A \beta$, such as isoaspartyl residues (at positions 1 and $7^{181,182}$ ) and pyroglutamyl formation (at position $3^{183}$ ).

Semisynthesis and total synthetic approaches represent the ideal strategies for the site-specific introduction of PTMs in amyloid proteins and hence allow unambiguous biochemical and structural studies of the modified variants. For the investigation of these modifications in cells and in vivo, we are still limited by the amount of proteins that can be delivered to cells either by microinjection, microelectroporation, or through the use of delivery reagents. While the first two techniques may be used to study subcellular localization, cell-penetrating peptides (CPPs; see Ref. 184 for a review) offer an alternative that addresses the low number of transduced cells and cytotoxicity associated with microinjection and electroporation. ${ }^{185}$ These usually short sequences mediate the internalization of the attached cargo via several possible mechanisms, the most prevalent of which being endocytosis. ${ }^{186}$ Intracellular delivery of $\alpha$-syn has already been achieved using fusion protein constructs based on the human immunodeficiency virus-derived TAT sequence ${ }^{187,188}$ and suggested that low amounts of internalized TAT- $\alpha$-syn could protect against certain forms of oxidative stress and serum deprivation through an increase in the HSP70 chaperone protein level. ${ }^{88}$ CPPs were also applied to internalize the 17-residue N-terminal fragment of Huntingtin into SH-SY5Y cells. ${ }^{189}$ This peptide had been shown in vitro to compete for oligomerization with longer, polyQ-containing N-terminal fragments of Huntingtin and, as a result, inhibit their amyloid formation propensity; however, the effects in cells have not yet been studied. ${ }^{189}$ One must bear in mind that covalent addition of even short sequences may perturb the function of the proteins of interest, especially due to the strongly cationic nature of many CPPs. This is the case with $\alpha$-syn, where polyarginines (which are part of some CPPs) were shown to accelerate oligomerization and fibrillization of $\alpha$-syn. ${ }^{187}$ To address this limitation, we note that covalent linkage of a cargo to a CPP may be designed to be reversible, for example, by a disulfide bond, which will be cleaved in the reducing environment of the cytosol (leaving, however, a free cysteine in the cargo, which may have been introduced artificially for that purpose), or if the CPP is attached by a photolabile linker (through protein semisynthesis), in which case regeneration of the cargo's native sequence is possible. However, these approaches have not yet been applied to study amyloidogenic proteins. In all cases, appropriate experimental design is crucial to ensure that the released CPPs do not alter the behavior of the proteins of interest once within the cell.

Protein-protein interactions can be studied in the presence of cell lysate in the case where the semisynthetic or total synthetic protein has been modified to allow for a handle. Other studies in vivo would still require the over-expression of the enzyme that is responsible for the PTMs or the use of phosphomimics. The comparison of the phosphomimics and the semisynthetic or total synthetic 
phosphorylated protein, particularly with respect to aggregation propensity, would further confirm whether their use could be of significant relevance in vivo.

The different strategies outlined above (total chemical synthesis and EPL) represent powerful methodologies that allow the introduction of sitespecific chemical modifications and/or PTMs including glycosylation, ${ }^{78,190,191}$ lipidation, ${ }^{78,102,192}$ ubiquitination, ${ }^{139,193}$ D-amino acids, ${ }^{194}$ and phosphorylation $^{74,195}$ among many others. These approaches have been widely used to site-specifically introduce fluorescent probes, fluorescence resonance energy transfer pairs, or affinity handles to allow for selective labeling at specific residues using small probes or the covalent immobilization or cross-linking of proteins using the handles (for review, see Ref. 99). Nonhydrolyzable phosphonate amino acids have been synthesized and incorporated into proteins to prevent rapid dephosphorylation at Ser or Tyr. ${ }^{196}$

\section{Conclusion}

The various examples presented in this article illustrate the power and potential of applying recent advances in synthetic organic chemistry, protein synthesis, and chemical biology to provide important insight into the molecular determinants and mechanisms that govern amyloid formation and toxicity. Furthermore, the mechanistic insight gained through the use of these tools has not only helped in explaining biological findings but also contributed significantly to the design of biological experiments and guiding future efforts to model these processes in vivo. ${ }^{124,131,132}$ More novel chemical tools and approaches are needed. However, more proactive engagement between scientists from the different disciplines is necessary for these tools to realize their full potential and to drive the generation new biology-driven tools to address many of the current challenges facing the field today. We hope that this review will help promoting more interactions and collaborations on amyloid research at the interfaces of chemistry, biology, biochemistry, and biophysics. We believe that such collaborations will lead to exciting discoveries and usher a new era in chemical biology of amyloid research and neurodegeneration.

\section{Acknowledgements}

This work was supported by European Research Council starting grant (243182), Human Frontiers Science Program, young investigator grant (HLA, $\mathrm{AL})$, and funding from the Swiss National Science
Foundation (31003A_120653) and the Swiss Federal Institute of Technology. We would like to thank and dedicate this review to Prof. Manfred Mutter for his continued support and inspiring us to work in this field of molecular switches for protein folding and self-assembly. We also thank Prof. Ashraf Brik for his support, insightful discussion, and past and future exciting collaborations.

\section{References}

1. Abedini, A. \& Raleigh, D. P. (2005). Incorporation of pseudoproline derivatives allows the facile synthesis of human IAPP, a highly amyloidogenic and aggregation-prone polypeptide. Org. Lett. 7, 693-696.

2. Sohma, Y. \& Kiso, Y. (2006). "Click peptides"—chemical biology-oriented synthesis of Alzheimer's diseaserelated amyloid $\beta$ peptide $(A \beta)$ analogues based on the "O-acyl isopeptide method". ChemBioChem, 7, 1549-1557.

3. Sohma, Y., Sasaki, M., Hayashi, Y., Kimura, T. \& Kiso, Y. (2004). Novel and efficient synthesis of difficult sequence-containing peptides through $\mathrm{O}-\mathrm{N}$ intramolecular acyl migration reaction of $\mathrm{O}$-acyl isopeptides. Chem. Commun. 124-125.

4. Sohma, Y., Hayashi, Y., Skwarczynski, M., Hamada, Y., Sasaki, M., Kimura, T. \& Kiso, Y. (2004). O-N intramolecular acyl migration reaction in the development of prodrugs and the synthesis of difficult sequence-containing bioactive peptides. Biopolymers, 76, 344-356.

5. Tickler, A. K., Clippingdale, A. B. \& Wade, J. D. (2004). Amyloid- $\beta$ as a "difficult sequence" in solid phase peptide synthesis. Protein Pept. Lett. 11, 377-384.

6. Zarandi, M., Soos, K., Fulop, L., Bozso, Z., Datki, Z., Toth, G. K. \& Penke, B. (2007). Synthesis of $\mathrm{A} \beta[1-42]$ and its derivatives with improved efficiency. J. Pept. Sci. 13, 94-99.

7. Gordon, D. J., Sciarretta, K. L. \& Meredith, S. C. (2001). Inhibition of $\beta$-amyloid(40) fibrillogenesis and disassembly of $\beta$-amyloid(40) fibrils by short $\beta$-amyloid congeners containing $N$-methyl amino acids at alternate residues. Biochemistry, 40, 8237-8245.

8. Kapurniotu, A., Schmauder, A. \& Tenidis, K. (2002). Structure-based design and study of nonamyloidogenic, double N-methylated IAPP amyloid core sequences as inhibitors of IAPP amyloid formation and cytotoxicity. J. Mol. Biol. 315, 339-350.

9. Pratim Bose, P., Chatterjee, U., Nerelius, C., Govender, T., Norstrom, T., Gogoll, A. et al. (2009). Poly- $N$-methylated amyloid $\beta$-peptide $(\mathrm{A} \beta) \mathrm{C}$-terminal fragments reduce $A \beta$ toxicity in vitro and in Drosophila melanogaster. J. Med. Chem. 52, 8002-8009.

10. Hughes, E., Burke, R. M. \& Doig, A. J. (2000). Inhibition of toxicity in the $\beta$-amyloid peptide fragment $\beta-(25-35)$ using $N$-methylated derivatives: a general strategy to prevent amyloid formation. J. Biol. Chem. 275, 25109-25115.

11. Yan, L. M., Tatarek-Nossol, M., Velkova, A., Kazantzis, A. \& Kapurniotu, A. (2006). Design of a mimic of nonamyloidogenic and bioactive human islet amyloid polypeptide (IAPP) as nanomolar affinity inhibitor of 
IAPP cytotoxic fibrillogenesis. Proc. Natl Acad. Sci. USA, 103, 2046-2051.

12. Madine, J., Doig, A. J. \& Middleton, D. A. (2008). Design of an N-methylated peptide inhibitor of $\alpha$-synuclein aggregation guided by solid-state NMR. J. Am. Chem. Soc. 130, 7873-7881.

13. Sciarretta, K. L., Boire, A., Gordon, D. J. \& Meredith, S. C. (2006). Spatial separation of $\beta$-sheet domains of $\beta$-amyloid: disruption of each $\beta$-sheet by $N$-methyl amino acids. Biochemistry, 45, 9485-9495.

14. Gordon, D. J. \& Meredith, S. C. (2003). Probing the role of backbone hydrogen bonding in $\beta$-amyloid fibrils with inhibitor peptides containing ester bonds at alternate positions. Biochemistry, 42, 475-485.

15. Bieschke, J., Siegel, S. J., Fu, Y. \& Kelly, J. W. (2008). Alzheimer's $A \beta$ peptides containing an isostructural backbone mutation afford distinct aggregate morphologies but analogous cytotoxicity. Evidence for a common low-abundance toxic structure(s)? Biochemistry, 47, 50-59.

16. Fu, Y., Bieschke, J. \& Kelly, J. W. (2005). E-Olefin dipeptide isostere incorporation into a polypeptide backbone enables hydrogen bond perturbation: probing the requirements for Alzheimer's amyloidogenesis. J. Am. Chem. Soc. 127, 15366-15367.

17. Wohr, T., Wahl, F., Nefzi, A., Rohwedder, B., Sato, T., Sun, X. C. \& Mutter, M. (1996). Pseudo-prolines as a solubilizing, structure-disrupting protection technique in peptide synthesis. J. Am. Chem. Soc. 118, 9218-9227.

18. Tuchscherer, G., Chandravarkar, A., Camus, M. S., Berard, J., Murat, K., Schmid, A. et al. (2007). Switchpeptides as folding precursors in self-assembling peptides and amyloid fibrillogenesis. Biopolymers, $\mathbf{8 8}$, 239-252.

19. Coin, I., Dolling, R., Krause, E., Bienert, M., Beyermann, M., Sferdean, C. D. \& Carpino, L. A. (2006). Depsipeptide methodology for solid-phase peptide synthesis: circumventing side reactions and development of an automated technique via depsidipeptide units. J. Org. Chem. 71, 6171-6177.

20. Coin, I. (2010). The depsipeptide method for solidphase synthesis of difficult peptides. J. Pept. Sci. 16, 223-230.

21. Taniguchi, A., Yoshiya, T., Abe, N., Fukao, F., Sohma, Y., Kimura, T. et al. (2007). "O-Acyl isopeptide method" for peptide synthesis: solvent effects in the synthesis of A $\beta 1-42$ isopeptide using "O-acyl isodipeptide unit". J. Pept. Sci. 13, 868-874.

22. Mutter, M., Chandravarkar, A., Boyat, C., Lopez, J., Dos Santos, S., Mandal, B. et al. (2004). Switch peptides in statu nascendi: induction of conformational transitions relevant to degenerative diseases. Angew. Chem., Int. Ed. Engl. 43, 4172-4178.

23. Taniguchi, A., Sohma, Y., Hirayama, Y., Mukai, H., Kimura, T., Hayashi, Y. et al. (2009). "Click peptide": $\mathrm{pH}$-triggered in situ production and aggregation of monomer A $\beta 1-42$. ChemBioChem, 10, 710-715.

24. Mimna, R., Camus, M. S., Schmid, A., Tuchscherer, G., Lashuel, H. A. \& Mutter, M. (2007). Disruption of amyloid-derived peptide assemblies through the controlled induction of a $\beta$-sheet to $\alpha$-helix transformation: application of the switch concept. Angew. Chem., Int. Ed. Engl. 46, 2681-2684.
25. Wang, H., Kakizawa, T., Taniguchi, A., Mizuguchi, T., Kimura, T. \& Kiso, Y. (2009). Synthesis of amyloid $\beta$ peptide 1-42 (E22 $\Delta$ ) click peptide: $\mathrm{pH}$-triggered in situ production of its native form. Bioorg. Med. Chem. 17, 4881-4887.

26. Sohma, Y., Hayashi, Y., Kimura, M., Chiyomori, Y., Taniguchi, A., Sasaki, M. et al. (2005). The "O-acyl isopeptide method" for the synthesis of difficult sequence-containing peptides: application to the synthesis of Alzheimer's disease-related amyloid $\beta$ peptide (Aß) 1-42. J. Pept. Sci. 11, 441-451.

27. Dos Santos, S., Chandravarkar, A., Mandal, B., Mimna, R., Murat, K., Saucede, L. et al. (2005). Switch-peptides: controlling self-assembly of amyloid $\beta$-derived peptides in vitro by consecutive triggering of acyl migrations. J. Am. Chem. Soc. 127, 11888-11889.

28. Nepomniaschiy, N., Grimminger, V., Cohen, A., DiGiovanni, S., Lashuel, H. A. \& Brik, A. (2008). Switch peptide via Staudinger reaction. Org. Lett. 10, 5243-5246.

29. Taniguchi, A., Sohma, Y., Kimura, M., Okada, T., Ikeda, K., Hayashi, Y. et al. (2006). "Click peptide" based on the "O-acyl isopeptide method": control of A $\beta 1-42$ production from a phototriggered A $\beta 1-42$ analogue. J. Am. Chem. Soc. 128, 696-697.

30. Taniguchi, A., Skwarczynski, M., Sohma, Y., Okada, T., Ikeda, K., Prakash, H. et al. (2008). Controlled production of amyloid $\beta$ peptide from a phototriggered, water-soluble precursor "click peptide". ChemBioChem, 9, 3055-3065.

31. Camus, M. S., Dos Santos, S., Chandravarkar, A., Mandal, B., Schmid, A. W., Tuchscherer, G. et al. (2008). Switch-peptides: design and characterization of controllable super-amyloid-forming host-guest peptides as tools for identifying anti-amyloid agents. ChemBioChem, 9, 2104-2112.

32. Sohma, Y., Chiyomori, Y., Kimura, M., Fukao, F., Taniguchi, A., Hayashi, Y. et al. (2005). "O-Acyl isopeptide method" for the efficient preparation of amyloid $\beta$ peptide 1-42 mutants. Bioorg. Med. Chem. 13, 6167-6174.

33. Sohma, Y., Hirayama, Y., Taniguchi, A., Mukai, H. \& Kiso, Y. (2011). "Click peptide" using production of monomer $\mathrm{A} \beta$ from the $O$-acyl isopeptide: application to assay system of aggregation inhibitors and cellular cytotoxicity. Bioorg. Med. Chem. 19, 1729-1733.

34. Yoshiya, T., Higa, A., Abe, N., Fukao, F., Kuruma, T., Toda, Y. et al. (2011). Click Peptide concept: O-acyl isopeptide of islet amyloid polypeptide as a nonaggregative precursor molecule. ChemBioChem, 12, 1216-1222.

35. Bozso, Z., Penke, B., Simon, D., Laczko, I., Juhasz, G., Szegedi, V. et al. (2010). Controlled in situ preparation of $A \beta(1-42)$ oligomers from the isopeptide "iso-A $\beta(1-42)$ ", physicochemical and biological characterization. Peptides, 31, 248-256.

36. Porat, Y., Abramowitz, A. \& Gazit, E. (2006). Inhibition of amyloid fibril formation by polyphenols: structural similarity and aromatic interactions as a common inhibition mechanism. Chem. Biol. Drug Des. 67, 27-37. 
37. Cohen, T., Frydman-Marom, A., Rechter, M. \& Gazit, E. (2006). Inhibition of amyloid fibril formation and cytotoxicity by hydroxyindole derivatives. Biochemistry, 45, 4727-4735.

38. Lashuel, H. A., Hartley, D. M., Balakhaneh, D., Aggarwal, A., Teichberg, S. \& Callaway, D. J. (2002). New class of inhibitors of amyloid- $\beta$ fibril formation. Implications for the mechanism of pathogenesis in Alzheimer's disease. J. Biol. Chem. 277, 42881-42890.

39. Mayer, G. \& Heckel, A. (2006). Biologically active molecules with a "light switch". Angew. Chem., Int. Ed. Engl. 45, 4900-4921.

40. Bosques, C. J. \& Imperiali, B. (2003). Photolytic control of peptide self-assembly. J. Am. Chem. Soc. 125, 7530-7531.

41. Haines, L. A., Rajagopal, K., Ozbas, B., Salick, D. A., Pochan, D. J. \& Schneider, J. P. (2005). Light-activated hydrogel formation via the triggered folding and self-assembly of a designed peptide. J. Am. Chem. Soc. 127, 17025-17029.

42. Muraoka, T., Koh, C. Y., Cui, H. \& Stupp, S. I. (2009). Light-triggered bioactivity in three dimensions. Angew. Chem., Int. Ed. Engl. 48, 5946-5949.

43. Fancy, D. A. \& Kodadek, T. (1999). Chemistry for the analysis of protein-protein interactions: rapid and efficient cross-linking triggered by long wavelength light. Proc. Natl Acad. Sci. USA, 96, 6020-6024.

44. Chin, J. W. \& Schultz, P. G. (2002). In vivo photocrosslinking with unnatural amino acid mutagenesis. ChemBioChem, 3, 1135-1137.

45. Tanaka, Y., Bond, M. R. \& Kohler, J. J. (2008). Photocrosslinkers illuminate interactions in living cells. Mol. Biosyst. 4, 473-480.

46. Smith, D. P., Anderson, J., Plante, J., Ashcroft, A. E., Radford, S. E., Wilson, A. J. \& Parker, M. J. (2008). Trifluoromethyldiazirine: an effective photo-induced cross-linking probe for exploring amyloid formation. Chem. Commun. 5728-5730.

47. Hutchinson, E. G., Sessions, R. B., Thornton, J. M. \& Woolfson, D. N. (1998). Determinants of strand register in antiparallel $\beta$-sheets of proteins. Protein Sci. 7, 2287-2300.

48. Bitan, G., Kirkitadze, M. D., Lomakin, A., Vollers, S. S., Benedek, G. B. \& Teplow, D. B. (2003). Amyloid $\beta$-protein $(A \beta)$ assembly: $A \beta 40$ and $A \beta 42$ oligomerize through distinct pathways. Proc. Natl Acad. Sci. USA, 100, 330-335.

49. Ono, K., Condron, M. M. \& Teplow, D. B. (2009). Structure-neurotoxicity relationships of amyloid B-protein oligomers. Proc. Natl Acad. Sci. USA, 106, 14745-14750.

50. Balbach, J. J., Ishii, Y., Antzutkin, O. N., Leapman, R. D., Rizzo, N. W., Dyda, F. et al. (2000). Amyloid fibril formation by $A \beta_{16-22}$, a seven-residue fragment of the Alzheimer's $\beta$-amyloid peptide, and structural characterization by solid state NMR. Biochemistry, 39, 13748-13759.

51. Suchanek, M., Radzikowska, A. \& Thiele, C. (2005). Photo-leucine and photo-methionine allow identification of protein-protein interactions in living cells. Nat. Methods, 2, 261-267.

52. Bacsa, B., Bosze, S. \& Kappe, C. O. (2010). Direct solid-phase synthesis of the $\beta$-amyloid (1-42) peptide using controlled microwave heating. J. Org. Chem. 75, 2103-2106.

53. Wang, L. \& Schultz, P. G. (2004). Expanding the genetic code. Angew. Chem., Int. Ed. Engl. 44, 34-66.

54. Bitan, G., Lomakin, A. \& Teplow, D. B. (2001). Amyloid $\beta$-protein oligomerization: prenucleation interactions revealed by photo-induced cross-linking of unmodified proteins. J. Biol. Chem. 276, 35176-35184.

55. Jarrett, J. T. \& Lansbury, P. T., Jr (1993). Seeding "one-dimensional crystallization" of amyloid: a pathogenic mechanism in Alzheimer's disease and scrapie? Cell, 73, 1055-1058.

56. Lomakin, A., Chung, D. S., Benedek, G. B., Kirschner, D. A. \& Teplow, D. B. (1996). On the nucleation and growth of amyloid $\beta$-protein fibrils: detection of nuclei and quantitation of rate constants. Proc. Natl Acad. Sci. USA, 93, 1125-1129.

57. Lomakin, A., Teplow, D. B., Kirschner, D. A. \& Benedek, G. B. (1997). Kinetic theory of fibrillogenesis of amyloid $\beta$-protein. Proc. Natl Acad. Sci. USA, 94, 7942-7947.

58. Walsh, D. M., Klyubin, I., Fadeeva, J. V., Cullen, W. K., Anwyl, R., Wolfe, M. S. et al. (2002). Naturally secreted oligomers of amyloid $\beta$ protein potently inhibit hippocampal long-term potentiation in vivo. Nature, 416, 535-539.

59. Cleary, J. P., Walsh, D. M., Hofmeister, J. J., Shankar, G. M., Kuskowski, M. A., Selkoe, D. J. \& Ashe, K. H. (2005). Natural oligomers of the amyloid- $\beta$ protein specifically disrupt cognitive function. Nat. Neurosci. 8, 79-84.

60. Lesne, S., Koh, M. T., Kotilinek, L., Kayed, R., Glabe, C. G., Yang, A. et al. (2006). A specific amyloid- $\beta$ protein assembly in the brain impairs memory. Nature, 440, 352-357.

61. Townsend, M., Shankar, G. M., Mehta, T., Walsh, D. M. \& Selkoe, D. J. (2006). Effects of secreted oligomers of amyloid $\beta$-protein on hippocampal synaptic plasticity: a potent role for trimers. J. Physiol. 572, 477-492.

62. Hung, L. W., Ciccotosto, G. D., Giannakis, E., Tew, D. J., Perez, K., Masters, C. L. et al. (2008). Amyloid- $\beta$ peptide $(A \beta)$ neurotoxicity is modulated by the rate of peptide aggregation: $A \beta$ dimers and trimers correlate with neurotoxicity. J. Neurosci. 28, 11950-11958.

63. Shankar, G. M., Li, S., Mehta, T. H., Garcia-Munoz, A., Shepardson, N. E., Smith, I. et al. (2008). Amyloid- $\beta$ protein dimers isolated directly from Alzheimer's brains impair synaptic plasticity and memory. Nat. Med. 14, 837-842.

64. Haass, C. \& Selkoe, D. J. (2007). Soluble protein oligomers in neurodegeneration: lessons from the Alzheimer's amyloid $\beta$-peptide. Nat. Rev., Mol. Cell Biol. 8, 101-112.

65. Peterson, S. A., Klabunde, T., Lashuel, H. A., Purkey, H., Sacchettini, J. C. \& Kelly, J. W. (1998). Inhibiting transthyretin conformational changes that lead to amyloid fibril formation. Proc. Natl Acad. Sci. USA, 95, 12956-12960.

66. Bitan, G. (2006). Structural study of metastable amyloidogenic protein oligomers by photo-induced cross-linking of unmodified proteins. Methods Enzymol. $413,217-236$. 
67. Piening, N., Weber, P., Hogen, T., Beekes, M., Kretzschmar, H. \& Giese, A. (2006). Photo-induced crosslinking of prion protein oligomers and prions. Amyloid, 13, 67-77.

68. Li, H. T., Lin, X. J., Xie, Y. Y. \& Hu, H. Y. (2006). The early events of $\alpha$-synuclein oligomerization revealed by photo-induced cross-linking. Protein Pept. Lett. 13, 385-390.

69. Boerema, D. J., Tereshko, V. A. \& Kent, S. B. (2008). Total synthesis by modern chemical ligation methods and high resolution (1.1 $\AA$ ) X-ray structure of ribonuclease A. Biopolymers, 90, 278-286.

70. Kent, S. B. (2009). Total chemical synthesis of proteins. Chem. Soc. Rev. 38, 338-351.

71. Olschewski, D. \& Becker, C. F. (2008). Chemical synthesis and semisynthesis of membrane proteins. Mol. Biosyst. 4, 733-740.

72. Bang, D. \& Kent, S. B. H. (2004). A one-pot total synthesis of crambin. Angew. Chem., Int. Ed. Engl. 43, 2534-2538.

73. Hackenberger, C. P. \& Schwarzer, D. (2008). Chemoselective ligation and modification strategies for peptides and proteins. Angew. Chem., Int. Ed. Engl. 47, 10030-10074.

74. Muir, T. W., Sondhi, D. \& Cole, P. A. (1998). Expressed protein ligation: a general method for protein engineering. Proc. Natl Acad. Sci. USA, 95, 6705-6710.

75. Flavell, R. R. \& Muir, T. W. (2009). Expressed protein ligation (EPL) in the study of signal transduction, ion conduction, and chromatin biology. Acc. Chem. Res. 42, 107-116.

76. Dawson, P. E., Muir, T. W., Clark-Lewis, I. \& Kent, S. B. (1994). Synthesis of proteins by native chemical ligation. Science, 266, 776-779.

77. Bockhorn, J. J., Lazar, K. L., Gasser, A. J., Luther, L. M., Qahwash, I. M., Chopra, N. \& Meredith, S. C. (2010). Novel semi-synthetic method for generating full length $\beta$-amyloid peptides. Biopolymers, 94, 511-520.

78. Becker, C. F., Liu, X., Olschewski, D., Castelli, R., Seidel, R. \& Seeberger, P. H. (2008). Semisynthesis of a glycosylphosphatidylinositol-anchored prion protein. Angew. Chem., Int. Ed. Engl. 47, 8215-8219.

79. Vila-Perello, M., Hori, Y., Ribo, M. \& Muir, T. W. (2008). Activation of protein splicing by protease- or light-triggered $\mathrm{O}$ to $\mathrm{N}$ acyl migration. Angew. Chem., Int. Ed. Engl. 47, 7764-7767.

80. Johnson, G. V. \& Stoothoff, W. H. (2004). Tau phosphorylation in neuronal cell function and dysfunction. J. Cell Sci. 117, 5721-5729.

81. Fujiwara, H., Hasegawa, M., Dohmae, N., Kawashima, A., Masliah, E., Goldberg, M. S. et al. (2002). $\alpha$-Synuclein is phosphorylated in synucleinopathy lesions. Nat. Cell Biol. 4, 160-164.

82. Tickler, A. K., Barrow, C. J. \& Wade, J. D. (2001). Improved preparation of amyloid- $\beta$ peptides using DBU as $N^{\alpha}$-Fmoc deprotection reagent. J. Pept. Sci. 7, 488-494.

83. Hood, C. A., Fuentes, G., Patel, H., Page, K., Menakuru, M. \& Park, J. H. (2008). Fast conventional Fmoc solid-phase peptide synthesis with HCTU. J. Pept. Sci. 14, 97-101.

84. Singer, D., Zauner, T., Genz, M., Hoffmann, R. \& Zuchner, T. (2010). Synthesis of pathological and nonpathological human exon 1 huntingtin. J. Pept. Sci. 16, 358-363.

85. Wan, Q. \& Danishefsky, S. J. (2007). Free-radicalbased, specific desulfurization of cysteine: a powerful advance in the synthesis of polypeptides and glycopolypeptides. Angew. Chem., Int. Ed. Engl. 46, 9248-9252.

86. Yan, L. Z. \& Dawson, P. E. (2001). Synthesis of peptides and proteins without cysteine residues by native chemical ligation combined with desulfurization. J. Am. Chem. Soc. 123, 526-533.

87. Crich, D. \& Banerjee, A. (2007). Native chemical ligation at phenylalanine. J. Am. Chem. Soc. 129, 10064-10065.

88. Chen, J., Wan, Q., Yuan, Y., Zhu, J. \& Danishefsky, S. J. (2008). Native chemical ligation at valine: a contribution to peptide and glycopeptide synthesis. Angew. Chem., Int. Ed. Engl. 47, 8521-8524.

89. Haase, C., Rohde, H. \& Seitz, O. (2008). Native chemical ligation at valine. Angew. Chem., Int. Ed. Engl. 47, 6807-6810.

90. Chen, J., Wang, P., Zhu, J., Wan, Q. \& Danishefsky, S. J. (2010). A program for ligation at threonine sites: application to the controlled total synthesis of glycopeptides. Tetrahedron, 66, 2277-2283.

91. Harpaz, Z., Siman, P., Kumar, K. S. \& Brik, A. (2010). Protein synthesis assisted by native chemical ligation at leucine. ChemBioChem, 11, 1232-1235.

92. Dawson, P. E. \& Kent, S. B. (2000). Synthesis of native proteins by chemical ligation. Annu. Rev. Biochem. 69, 923-960.

93. Kumar, K. S., Bavikar, S. N., Spasser, L., Moyal, T., Ohayon, S. \& Brik, A. (2011). Total chemical synthesis of a 304 amino acid K48-linked tetraubiquitin protein. Angew. Chem., Int. Ed. Engl. 50, 6137-6141.

94. Wlodawer, A., Miller, M., Jaskolski, M., Sathyanarayana, B. K., Baldwin, E., Weber, I. T. et al. (1989). Conserved folding in retroviral proteases: crystal structure of a synthetic HIV-1 protease. Science, 245, 616-621.

95. Hackeng, T. M., Mounier, C. M., Bon, C., Dawson, P. E., Griffin, J. H. \& Kent, S. B. (1997). Total chemical synthesis of enzymatically active human type II secretory phospholipase A2. Proc. Natl Acad. Sci. USA, 94, 7845-7850.

96. Durek, T., Torbeev, V. Y. \& Kent, S. B. (2007). Convergent chemical synthesis and high-resolution X-ray structure of human lysozyme. Proc. Natl Acad. Sci. USA, 104, 4846-4851.

97. Kochendoerfer, G. G., Salom, D., Lear, J. D., WilkOrescan, R., Kent, S. B. \& DeGrado, W. F. (1999). Total chemical synthesis of the integral membrane protein influenza A virus M2: role of its C-terminal domain in tetramer assembly. Biochemistry, 38, 11905-11913.

98. Evans, T. C., Jr, Benner, J. \& Xu, M. Q. (1998). Semisynthesis of cytotoxic proteins using a modified protein splicing element. Protein Sci. 7, 2256-2264.

99. Muir, T. W. (2003). Semisynthesis of proteins by expressed protein ligation. Annu. Rev. Biochem. 72, 249-289.

100. Gentle, I. E., De Souza, D. P. \& Baca, M. (2004). Direct production of proteins with N-terminal cysteine for site-specific conjugation. Bioconjug. Chem. 15, 658-663. 
101. Chiang, K. P., Jensen, M. S., McGinty, R. K. \& Muir, T. W. (2009). A semisynthetic strategy to generate phosphorylated and acetylated histone H2B. ChemBioChem, 10, 2182-2187.

102. Olschewski, D., Seidel, R., Miesbauer, M., Rambold, A. S., Oesterhelt, D., Winklhofer, K. F. et al. (2007). Semisynthetic murine prion protein equipped with a GPI anchor mimic incorporates into cellular membranes. Chem. Biol. 14, 994-1006.

103. Liu, X. Q. (2000). Protein-splicing intein: genetic mobility, origin, and evolution. Annu. Rev. Genet. 34 61-76.

104. Chong, S., Shao, Y., Paulus, H., Benner, J., Perler, F. B. \& Xu, M. Q. (1996). Protein splicing involving the Saccharomyces cerevisiae VMA intein. The steps in the splicing pathway, side reactions leading to protein cleavage, and establishment of an in vitro splicing system. J. Biol. Chem. 271, 22159-22168.

105. Xu, M. Q. \& Perler, F. B. (1996). The mechanism of protein splicing and its modulation by mutation. EMBO J. 15, 5146-5153.

106. Chong, S. \& Xu, M. Q. (1997). Protein splicing of the Saccharomyces cerevisiae VMA intein without the endonuclease motifs. J. Biol. Chem. 272, 15587-15590.

107. Blanco-Canosa, J. B. \& Dawson, P. E. (2008). An efficient Fmoc-SPPS approach for the generation of thioester peptide precursors for use in native chemical ligation. Angew. Chem., Int. Ed. Engl. 47, 6851-6855.

108. Szewczuk, L. M., Tarrant, M. K. \& Cole, P. A. (2009). Protein phosphorylation by semisynthesis: from paper to practice. Methods Enzymol. 462, 1-24.

109. Noren, C. J., Anthony-Cahill, S. J., Griffith, M. C. \& Schultz, P. G. (1989). A general method for sitespecific incorporation of unnatural amino acids into proteins. Science, 244, 182-188.

110. Young, T. S. \& Schultz, P. G. (2010). Beyond the canonical 20 amino acids: expanding the genetic lexicon. J. Biol. Chem. 285, 11039-11044.

111. England, P. M., Lester, H. A., Davidson, N. \& Dougherty, D. A. (1997). Site-specific, photochemical proteolysis applied to ion channels in vivo. Proc. Natl Acad. Sci. USA, 94, 11025-11030.

112. Miller, J. C., Silverman, S. K., England, P. M., Dougherty, D. A. \& Lester, H. A. (1998). Flash decaging of tyrosine sidechains in an ion channel. Neuron, 20, 619-624.

113. Tong, Y., Brandt, G. S., Li, M., Shapovalov, G., Slimko, E., Karschin, A. et al. (2001). Tyrosine decaging leads to substantial membrane trafficking during modulation of an inward rectifier potassium channel. J. Gen. Physiol. 117, 103-118.

114. Philipson, K. D., Gallivan, J. P., Brandt, G. S., Dougherty, D. A. \& Lester, H. A. (2001). Incorporation of caged cysteine and caged tyrosine into a transmembrane segment of the nicotinic ACh receptor. Am. J. Physiol.: Cell Physiol. 281, C195-C206.

115. Wang, W., Takimoto, J. K., Louie, G. V., Baiga, T. J., Noel, J. P., Lee, K. F. et al. (2007). Genetically encoding unnatural amino acids for cellular and neuronal studies. Nat. Neurosci. 10, 1063-1072.

116. Stromgaard, A., Jensen, A. A. \& Stromgaard, K. (2004). Site-specific incorporation of unnatural amino acids into proteins. ChemBioChem, 5, 909-916.
117. Spillantini, M. G., Schmidt, M. L., Lee, V. M., Trojanowski, J. Q., Jakes, R. \& Goedert, M. (1997). $\alpha$-Synuclein in Lewy bodies. Nature, 388, 839-840.

118. Trojanowski, J. Q. \& Lee, V. M. (2003). Parkinson's disease and related $\alpha$-synucleinopathies are brain amyloidoses. Ann. N. Y. Acad. Sci. 991, 107-110.

119. Polymeropoulos, M. H., Lavedan, C., Leroy, E., Ide, S. E., Dehejia, A., Dutra, A. et al. (1997). Mutation in the $\alpha$-synuclein gene identified in families with Parkinson's disease. Science, 276, 2045-2047.

120. Kruger, R., Kuhn, W., Muller, T., Woitalla, D., Graeber, M., Kosel, S. et al. (1998). Ala30Pro mutation in the gene encoding $\alpha$-synuclein in Parkinson's disease. Nat. Genet. 18, 106-108.

121. Zarranz, J. J., Alegre, J., Gomez-Esteban, J. C., Lezcano, E., Ros, R., Ampuero, I. et al. (2004). The new mutation, E46K, of $\alpha$-synuclein causes Parkinson and Lewy body dementia. Ann. Neurol. 55, 164-173.

122. Chartier-Harlin, M. C., Kachergus, J., Roumier, C., Mouroux, V., Douay, X., Lincoln, S. et al. (2004). $\alpha-$ Synuclein locus duplication as a cause of familial Parkinson's disease. Lancet, 364, 1167-1169.

123. Anderson, J. P., Walker, D. E., Goldstein, J. M., de Laat, R., Banducci, K., Caccavello, R. J. et al. (2006). Phosphorylation of Ser-129 is the dominant pathological modification of $\alpha$-synuclein in familial and sporadic Lewy body disease. J. Biol. Chem. 281, 29739-29752.

124. Oueslati, A., Fournier, M. \& Lashuel, H. A. (2010). Role of post-translational modifications in modulating the structure, function and toxicity of $\alpha$ synuclein: implications for Parkinson's disease pathogenesis and therapies. Prog. Brain Res. 183, 115-145.

125. Okochi, M., Walter, J., Koyama, A., Nakajo, S., Baba, M., Iwatsubo, T. et al. (2000). Constitutive phosphorylation of the Parkinson's disease associated $\alpha$ synuclein. J. Biol. Chem. 275, 390-397.

126. Pronin, A. N., Morris, A. J., Surguchov, A. \& Benovic, J. L. (2000). Synucleins are a novel class of substrates for $G$ protein-coupled receptor kinases. J. Biol. Chem. 275, 26515-26522.

127. Inglis, K. J., Chereau, D., Brigham, E. F., Chiou, S. S., Schobel, S., Frigon, N. L. et al. (2009). Polo-like kinase 2 (PLK2) phosphorylates $\alpha$-synuclein at serine 129 in central nervous system. J. Biol. Chem. 284, 2598-2602.

128. Mbefo, M. K., Paleologou, K. E., Boucharaba, A., Oueslati, A., Schell, H., Fournier, M. et al. (2010). Phosphorylation of synucleins by members of the Polo-like kinase family. J. Biol. Chem. 285, 2807-2822.

129. Nakamura, T., Yamashita, H., Takahashi, T. \& Nakamura, S. (2001). Activated Fyn phosphorylates $\alpha$-synuclein at tyrosine residue 125 . Biochem. Biophys. Res. Commun. 280, 1085-1092.

130. Negro, A., Brunati, A. M., Donella-Deana, A., Massimino, M. L. \& Pinna, L. A. (2002). Multiple phosphorylation of $\alpha$-synuclein by protein tyrosine kinase Syk prevents eosin-induced aggregation. FASEB J. 16, 210-212.

131. Paleologou, K. E., Schmid, A. W., Rospigliosi, C. C., Kim, H. Y., Lamberto, G. R., Fredenburg, R. A. et al. (2008). Phosphorylation at Ser-129 but not the 
phosphomimics S129E/D inhibits the fibrillation of

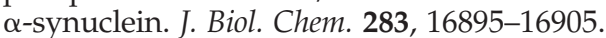

132. Paleologou, K. E., Oueslati, A., Shakked, G., Rospigliosi, C. C., Kim, H. Y., Lamberto, G. R. et al. (2010). Phosphorylation at S87 is enhanced in synucleinopathies, inhibits $\alpha$-synuclein oligomerization, and influences synuclein-membrane interactions. J. Neurosci. 30, 3184-3198.

133. Rott, R., Szargel, R., Haskin, J., Shani, V., Shainskaya, A., Manov, I. et al. (2008). Monoubiquitylation of $\alpha-$ synuclein by seven in absentia homolog (SIAH) promotes its aggregation in dopaminergic cells. J. Biol. Chem. 283, 3316-3328.

134. Lee, J. T., Wheeler, T. C., Li, L. \& Chin, L. S. (2008). Ubiquitination of $\alpha$-synuclein by Siah-1 promotes $\alpha$-synuclein aggregation and apoptotic cell death. Hum. Mol. Genet. 17, 906-917.

135. Kalia, L. V., Kalia, S. K., Chau, H., Lozano, A. M., Hyman, B. T. \& McLean, P. J. (2011). Ubiquitinylation of $\alpha$-synuclein by carboxyl terminus Hsp70-interacting protein $(\mathrm{CHIP})$ is regulated by Bcl-2-associated athanogene 5 (BAG5). PLoS One, 6, e14695.

136. Zucchelli, S., Codrich, M., Marcuzzi, F., Pinto, M., Vilotti, S., Biagioli, M. et al. (2010). TRAF6 promotes atypical ubiquitination of mutant DJ-1 and alphasynuclein and is localized to Lewy bodies in sporadic Parkinson's disease brains. Hum. Mol. Genet. 19, 3759-3770.

137. Mulherkar, S. A., Sharma, J. \& Jana, N. R. (2009). The ubiquitin ligase E6-AP promotes degradation of $\alpha$-synuclein. J. Neurochem. 110, 1955-1964.

138. Tofaris, G. K., Kim, H. T., Hourez, R., Jung, J. W., Kim, K. P. \& Goldberg, A. L. (2011). Ubiquitin ligase Nedd4 promotes $\alpha$-synuclein degradation by the endosomal-lysosomal pathway. Proc. Natl Acad. Sci. USA, 108, 17004-17009.

139. Hejjaoui, M., Haj-Yahya, M., Kumar, K. S., Brik, A. \& Lashuel, H. A. (2011). Towards elucidation of the role of ubiquitination in the pathogenesis of Parkinson's disease with semisynthetic ubiquitinated $\alpha$-synuclein. Angew. Chem., Int. Ed. Engl. 50, 405-409.

140. Ajish Kumar, K. S., Haj-Yahya, M., Olschewski, D., Lashuel, H. A. \& Brik, A. (2009). Highly efficient and chemoselective peptide ubiquitylation. Angew. Chem., Int. Ed. Engl. 48, 8090-8094.

141. Kumar, K. S., Spasser, L., Erlich, L. A., Bavikar, S. N. \& Brik, A. (2010). Total chemical synthesis of di-ubiquitin chains. Angew. Chem., Int. Ed. Engl. 49, 9126-9131.

142. Schilling, B., Gafni, J., Torcassi, C., Cong, X., Row, R. H., LaFevre-Bernt, M. A. et al. (2006). Huntingtin phosphorylation sites mapped by mass spectrometry. Modulation of cleavage and toxicity. J. Biol. Chem. 281, 23686-23697.

143. Gu, X., Greiner, E. R., Mishra, R., Kodali, R., Osmand, A., Finkbeiner, S. et al. (2009). Serines 13 and 16 are critical determinants of full-length human mutant huntingtin induced disease pathogenesis in HD mice. Neuron, 64, 828-840.

144. Steffan, J. S., Agrawal, N., Pallos, J., Rockabrand, E., Trotman, L. C., Slepko, N. et al. (2004). SUMO modification of Huntingtin and Huntington's disease pathology. Science, 304, 100-104.

145. Bavikar, S. N., Spasser, L., Haj-Yahya, M., Karthikeyan, S. V., Moyal, T., Ajish Kumar, K. S. \& Brik, A.
(2012). Chemical synthesis of ubiquitinated peptides with varying lengths and types of ubiquitin chains to explore the activity of deubiquitinases. Angew. Chem., Int. Ed. Engl. 51, 758-763.

146. Castaneda, C. A., Spasser, L., Bavikar, S. N., Brik, A. \& Fushman, D. (2011). Segmental isotopic labeling of ubiquitin chains to unravel monomer-specific molecular behavior. Angew. Chem., Int. Ed. Engl. 50, 11210-11214.

147. Hejjaoui, M., Butterfield, S. M., Fauvet, B., Vercruysse, F., Cui, J., Dikiy, I. et al. (2012). Elucidating the role of C-terminal post-translational modifications using protein semisynthesis strategies: alpha-synuclein phosphorylation at tyrosine 125. J. Am. Chem. Soc. In Press.

148. Ellis, C. E., Schwartzberg, P. L., Grider, T. L., Fink, D. W. \& Nussbaum, R. L. (2001). $\alpha$-Synuclein is phosphorylated by members of the Src family of protein-tyrosine kinases. J. Biol. Chem. 276, 3879-3884.

149. Chen, L., Periquet, M., Wang, X., Negro, A., McLean, P. J., Hyman, B. T. \& Feany, M. B. (2009). Tyrosine and serine phosphorylation of $\alpha$-synuclein have opposing effects on neurotoxicity and soluble oligomer formation. J. Clin. Invest. 119, 3257-3265.

150. Ahn, B. H., Rhim, H., Kim, S. Y., Sung, Y. M., Lee, M. Y., Choi, J. Y. et al. (2002). $\alpha$-Synuclein interacts with phospholipase D isozymes and inhibits pervanadate-induced phospholipase D activation in human embryonic kidney-293 cells. J. Biol. Chem. 277, 12334-12342.

151. Stahl, N., Borchelt, D. R., Hsiao, K. \& Prusiner, S. B. (1987). Scrapie prion protein contains a phosphatidylinositol glycolipid. Cell, 51, 229-240.

152. Pan, K. M., Baldwin, M., Nguyen, J., Gasset, M., Serban, A., Groth, D. et al. (1993). Conversion of $\alpha-$ helices into $\beta$-sheets features in the formation of the scrapie prion proteins. Proc. Natl Acad. Sci. USA, 90, 10962-10966.

153. Turk, E., Teplow, D. B., Hood, L. E. \& Prusiner, S. B. (1988). Purification and properties of the cellular and scrapie hamster prion proteins. Eur. J. Biochem. 176, 21-30.

154. Prusiner, S. B., Scott, M., Foster, D., Pan, K. M., Groth, D., Mirenda, C. et al. (1990). Transgenetic studies implicate interactions between homologous $\mathrm{PrP}$ isoforms in scrapie prion replication. Cell, 63, 673-686.

155. Meier, P., Genoud, N., Prinz, M., Maissen, M., Rulicke, T., Zurbriggen, A. et al. (2003). Soluble dimeric prion protein binds $\operatorname{PrP}(\mathrm{Sc})$ in vivo and antagonizes prion disease. Cell, 113, 49-60.

156. Morillas, M., Swietnicki, W., Gambetti, P. \& Surewicz, W. K. (1999). Membrane environment alters the conformational structure of the recombinant human prion protein. J. Biol. Chem. 274, 36859-36865.

157. Chesebro, B., Trifilo, M., Race, R., Meade-White, K., Teng, C., LaCasse, R. et al. (2005). Anchorless prion protein results in infectious amyloid disease without clinical scrapie. Science, 308, 1435-1439.

158. Eberl, H., Tittmann, P. \& Glockshuber, R. (2004). Characterization of recombinant, membraneattached full-length prion protein. J. Biol. Chem. 279, 25058-25065.

159. Hicks, M. R., Gill, A. C., Bath, I. K., Rullay, A. K., Sylvester, I. D., Crout, D. H. \& Pinheiro, T. J. (2006). 
Synthesis and structural characterization of a mimetic membrane-anchored prion protein. FEBS J. 273, 1285-1299.

160. Breydo, L., Sun, Y., Makarava, N., Lee, C. I., Novitskaia, V., Bocharova, O. et al. (2007). Nonpolar substitution at the C-terminus of the prion protein, a mimic of the glycosylphosphatidylinositol anchor, partially impairs amyloid fibril formation. Biochemistry, 46, 852-861.

161. Paulick, M. G. \& Bertozzi, C. R. (2008). The glycosylphosphatidylinositol anchor: a complex membraneanchoring structure for proteins. Biochemistry, 47, 6991-7000.

162. Baldwin, M. A. (2005). Analysis of glycosylphosphatidylinositol protein anchors: the prion protein. Methods Enzymol. 405, 172-187.

163. Durek, T. \& Becker, C. F. (2005). Protein semisynthesis: new proteins for functional and structural studies. Biomol. Eng. 22, 153-172.

164. Kochendoerfer, G. G., Clayton, D. \& Becker, C. (2005). Chemical synthesis approaches to the engineering of ion channels. Protein Peptide Lett. 12, 737-741.

165. Johnson, E. C. \& Kent, S. B. (2007). Towards the total chemical synthesis of integral membrane proteins: a general method for the synthesis of hydrophobic peptide- ${ }^{\alpha}$ thioester building blocks. Tetrahedron Lett. 48, 1795-1799.

166. Melnyk, R. A., Partridge, A. W., Yip, J., Wu, Y., Goto, N. K. \& Deber, C. M. (2003). Polar residue tagging of transmembrane peptides. Biopolymers, 71, 675-685.

167. Seidel, R. \& Engelhard, M. (2011). Chemical biology of prion protein: tools to bridge the in vitro/vivo interface. Top. Curr. Chem. 305, 199-223.

168. Giriat, I. \& Muir, T. W. (2003). Protein semi-synthesis in living cells. J. Am. Chem. Soc. 125, 7180-7181.

169. Vey, M., Pilkuhn, S., Wille, H., Nixon, R., DeArmond, S. J., Smart, E. J. et al. (1996). Subcellular colocalization of the cellular and scrapie prion proteins in caveolaelike membranous domains. Proc. Natl Acad. Sci. USA, 93, 14945-14949.

170. Schumacher, M. C., Resenberger, U., Seidel, R. P., Becker, C. F., Winklhofer, K. F., Oesterhelt, D. et al. (2010). Synthesis of a GPI anchor module suitable for protein post-translational modification. Biopolymers, 94, 457-464.

171. Braak, H. \& Braak, E. (1991). Neuropathological stageing of Alzheimer-related changes. Acta Neuropathol. 82, 239-259.

172. Wüthrich, K. (1986). NMR of Proteins and Nucleic Acids. John Wiley \& Sons, New York, NY.

173. Sharpe, S., Yau, W. M. \& Tycko, R. (2005). Expression and purification of a recombinant peptide from the Alzheimer's $\beta$-amyloid protein for solid-state NMR. Protein Expression Purif. 42, 200-210.

174. de Groot, N. S., Aviles, F. X., Vendrell, J. \& Ventura, S. (2006). Mutagenesis of the central hydrophobic cluster in $A \beta 42$ Alzheimer's peptide. Side-chain properties correlate with aggregation propensities. FEBS J. 273, 658-668.

175. Garai, K., Crick, S. L., Mustafi, S. M. \& Frieden, C. (2009). Expression and purification of amyloid- $\beta$ peptides from Escherichia coli. Protein Expression Purif. 66, 107-112.
176. Long, F., Cho, W. \& Ishii, Y. (2011). Expression and purification of ${ }^{15} \mathrm{~N}$ - and ${ }^{13} \mathrm{C}$-isotope labeled $40-$ residue human Alzheimer's $\beta$-amyloid peptide for NMR-based structural analysis. Protein Expression Purif. 79, 16-24.

177. Nagata-Uchiyama, M., Yaguchi, M., Hirano, Y. \& Ueda, T. (2007). Expression and purification of uniformly ${ }^{15} \mathrm{~N}$-labeled amyloid $\beta$ peptide 1-40 in Escherichia coli. Protein Pept. Lett. 14, 788-792.

178. Grabowski, T. J., Cho, H. S., Vonsattel, J. P., Rebeck, G. W. \& Greenberg, S. M. (2001). Novel amyloid precursor protein mutation in an Iowa family with dementia and severe cerebral amyloid angiopathy. Ann. Neurol. 49, 697-705.

179. Butterfield, D. A. \& Boyd-Kimball, D. (2005). The critical role of methionine 35 in Alzheimer's amyloid $\beta$-peptide (1-42)-induced oxidative stress and neurotoxicity. Biochim. Biophys. Acta, 1703, 149-156.

180. Maiti, P., Piacentini, R., Ripoli, C., Grassi, C. \& Bitan, G. (2011). Surprising toxicity and assembly behaviour of amyloid $\beta$-protein oxidized to sulfone. Biochem. J. 433, 323-332.

181. Roher, A. E., Lowenson, J. D., Clarke, S., Wolkow, C., Wang, R., Cotter, R. J. et al. (1993). Structural alterations in the peptide backbone of beta-amyloid core protein may account for its deposition and stability in Alzheimer's disease. J. Biol. Chem. 268, 3072-3083.

182. Roher, A. E., Lowenson, J. D., Clarke, S., Woods, A. S., Cotter, R. J., Gowing, E. \& Ball, M. J. (1993). ßAmyloid-(1-42) is a major component of cerebrovascular amyloid deposits: implications for the pathology of Alzheimer disease. Proc. Natl Acad. Sci. USA, 90, 10836-10840.

183. Kuo, Y. M., Emmerling, M. R., Woods, A. S., Cotter, R. J. \& Roher, A. E. (1997). Isolation, chemical characterization, and quantitation of $\mathrm{A} \beta$ 3-pyroglutamyl peptide from neuritic plaques and vascular amyloid deposits. Biochem. Biophys. Res. Commun. 237, 188-191.

184. Fonseca, S. B., Pereira, M. P. \& Kelley, S. O. (2009). Recent advances in the use of cell-penetrating peptides for medical and biological applications. Adv. Drug Deliver. Rev. 61, 953-964.

185. Lambert, H., Pankov, R., Gauthier, J. \& Hancock, R. (1990). Electroporation-mediated uptake of proteins into mammalian cells. Biochem. Cell Biol. 68, 729-734.

186. Madani, F., Lindberg, S., Langel, U., Futaki, S. \& Graslund, A. (2011). Mechanisms of cellular uptake of cell-penetrating peptides. J. Biophys. 2011, 414729.

187. Goers, J., Uversky, V. N. \& Fink, A. L. (2003). Polycation-induced oligomerization and accelerated fibrillation of human $\alpha$-synuclein in vitro. Protein Sci. 12, 702-707.

188. Albani, D., Peverelli, E., Rametta, R., Batelli, S., Veschini, L., Negro, A. \& Forloni, G. (2004). Protective effect of TAT-delivered $\alpha$-synuclein: relevance of the C-terminal domain and involvement of HSP70. FASEB J. 18, 1713-1715.

189. Mishra, R., Jayaraman, M., Roland, B. P., Landrum, E., Fullam, T., Kodali, R. et al. (2012). Inhibiting the nucleation of amyloid structure in a huntingtin fragment by targeting $\alpha$-helix-rich oligomeric intermediates. J. Mol. Biol. 415, 900-917. 
190. Macmillan, D. \& Bertozzi, C. R. (2004). Modular assembly of glycoproteins: towards the synthesis of GlyCAM-1 by using expressed protein ligation. Angew. Chem., Int. Ed. Engl. 43, 1355-1359.

191. Hackenberger, C. P., Friel, C. T., Radford, S. E. \& Imperiali, B. (2005). Semisynthesis of a glycosylated Im7 analogue for protein folding studies. J. Am. Chem. Soc. 127, 12882-12889.

192. Alexandrov, K., Heinemann, I., Durek, T., Sidorovitch, V., Goody, R. S. \& Waldmann, H. (2002). Inteinmediated synthesis of geranylgeranylated Rab7 protein in vitro. J. Am. Chem. Soc. 124, 5648-5649.

193. McGinty, R. K., Kim, J., Chatterjee, C., Roeder, R. G. \& Muir, T. W. (2008). Chemically ubiquitylated histone H2B stimulates hDot1L-mediated intranucleosomal methylation. Nature, 453, 812-816.

194. Valiyaveetil, F. I., Sekedat, M., Mackinnon, R. \& Muir, T. W. (2004). Glycine as a D-amino acid surrogate in the K-selectivity filter. Proc. Natl Acad. Sci. USA, 101, 17045-17049.

195. Huse, M., Muir, T. W., Xu, L., Chen, Y. G., Kuriyan, J. \& Massague, J. (2001). The TGF $\beta$ receptor activation process: an inhibitor- to substrate-binding switch. Mol. Cell, 8, 671-682.

196. Lu, W., Gong, D., Bar-Sagi, D. \& Cole, P. A. (2001). Site-specific incorporation of a phosphotyrosine mimetic reveals a role for tyrosine phosphorylation of SHP-2 in cell signaling. Mol. Cell, 8, 759-769. 